\title{
Competitiveness of a low specific power, low cut-out wind speed wind turbine in North
} and Central Europe towards 2050

Swisher, Philip; Murcia Leon, Juan Pablo; Gea-Bermúdez, Juan; Koivisto, Matti; Madsen, Helge Aagaard; Münster, Marie

Published in:

Applied Energy

Link to article, DOI:

10.1016/j.apenergy.2021.118043

Publication date:

2022

Document Version

Publisher's PDF, also known as Version of record

Link back to DTU Orbit

Citation (APA):

Swisher, P., Murcia Leon, J. P., Gea-Bermúdez, J., Koivisto, M., Madsen, H. A., \& Münster, M. (2022).

Competitiveness of a low specific power, low cut-out wind speed wind turbine in North and Central Europe towards 2050. Applied Energy, 304, [118043]. https://doi.org/10.1016/j.apenergy.2021.118043

\section{General rights}

Copyright and moral rights for the publications made accessible in the public portal are retained by the authors and/or other copyright owners and it is a condition of accessing publications that users recognise and abide by the legal requirements associated with these rights.

- Users may download and print one copy of any publication from the public portal for the purpose of private study or research.

- You may not further distribute the material or use it for any profit-making activity or commercial gain

- You may freely distribute the URL identifying the publication in the public portal 


\title{
Competitiveness of a low specific power, low cut-out wind speed wind turbine in North and Central Europe towards 2050
}

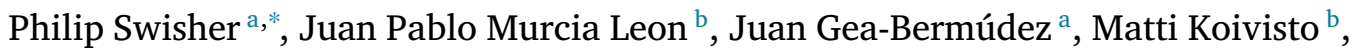 \\ Helge Aagaard Madsen ${ }^{\mathrm{b}}$, Marie Münster ${ }^{\mathrm{a}}$ \\ ${ }^{a}$ Technical University of Denmark, Department of Management, Produktionstorvet, Bygning 424, 2800 Kongens Lyngby, Denmark \\ ${ }^{\mathrm{b}}$ Technical University of Denmark, Department of Wind Energy, Roskilde, Denmark
}

\section{A R T I C L E I N F O}

\section{Keywords:}

Sector coupling

Optimization

Energy system

Modelling

Flexibility

Wind

\begin{abstract}
A B S T R A C T
This work is part of an ongoing study, creatively named the "LowWind Project" (Madsen et al., 2020), whose goal is to investigate at what price point a hypothetical $3.4 \mathrm{MW} 100 \mathrm{~W} / \mathrm{m}^{2}$ low wind (LW) turbine with a hub height of $127.5 \mathrm{~m}$, a rotor diameter of $208 \mathrm{~m}$, and a cut-out wind speed of $13 \mathrm{~m} / \mathrm{s}$ becomes competitive in Northern and Central Europe's energy system, as well as what impact the introduction of this technology has on the system. Similarly, the impact system flexibility has on LW investment is also analysed by limiting future transmission investment. Furthermore, this paper also analyses the amount of revenue this LW technology could generate compared to conventional turbines to further investigate the business case for this technology. The main finding here is that this LW technology begins to see investment at a $45 \%$ price increase over a conventional onshore wind turbine with an equal hub height $(127.5 \mathrm{~m})$ and a smaller rotor diameter (142 $\mathrm{m}$ vs $208 \mathrm{~m}$ ). The addition of LW technology also leads to a reduction in transmission investment, and similarly, reductions in transmission capacity lead to further investment in LW technology. Lastly, it is shown that in the future Northern and Central European energy system, in wind dominated areas such as Denmark, this LW technology could generate revenues that are more than double that of conventional turbines (per MW), making the case that this technology could be a worthy endeavor.
\end{abstract}

\section{Introduction}

In December 2019, the European Commission (EC) announced a European Green Deal, whose goal is to make Europe the first climateneutral continent [1]. Later on March 4th, 2020, as part of the European Green Deal, the EC proposed the first European Climate Law, whose purpose is to put the 2050 climate-neutrality target into law [2]. With this in mind, it appears ever more likely that the European energy system will continue to decarbonize, leading to increasing investments in wind and solar technologies. However, there are a number of problems that arise when variable renewable energy (VRE) technologies hold large shares of a system's energy mix. Two of these problems are the increased need for grid flexibility (which can be expensive [3]) and the 'self-cannibalization' effect, which occurs due to the zero marginal cost of solar and wind technology [4], where during hours of high VRE generation, electricity prices are near-zero, causing VRE generation to produce little revenue during, for example, very sunny and/or windy periods. Left unsolved, these two problems can slow down the climateneutral transition, and at worst could stop it in its tracks, as wind and solar plants could struggle to generate revenue while also increasing costs to the system.

\subsection{Motivation}

One solution that could both reduce the need for flexibility and alleviate this 'self-cannibalization' effect is low wind (LW) turbine technology, which generates electricity during a significantly larger portion of the year than conventional turbines, leading to a reduced need for flexibility (due to fewer hours of high net load) as well as renewable generation during periods where other wind turbines are not generating (which counters self-cannibalization) [5]. To be clear, what is meant here by "LW technology" is not merely wind turbines with low specific power, rather it refers to the wind turbine described here [6], where both specific power and cut-out wind speed (WS) are uniquely low. This low cut-out WS is particularly important, as it helps solve the aforementioned problems by not producing during high wind events while at the same time reducing costs as it allows the turbine blades

\footnotetext{
* Corresponding author.

E-mail address: phisw@dtu.dk (P. Swisher).
} 


$\begin{array}{ll}\text { Nomenclature } & \\ A E P & \text { Annual energy production } \\ B E V & \text { Battery electric vehicle } \\ C a p E x & \text { Capital expenditure (i.e. upfront cost) } \\ C F & \text { Capacity factor: } \frac{F L H}{8760} \cdot 100[\%] \\ C H P & \text { Combined heat and power plant } \\ E V & \text { Electric vehicle } \\ F L H & \text { Full-load hours: } \frac{A E P}{\text { Rated Power }}[\mathrm{h}] \\ L C O E & \text { Levelized cost of electricity } \frac{\text { Lifetime cost }}{\text { Lifetime Production }} \\ & \text { [€/MWh] } \\ L W & \text { Low wind } \\ O p E x & \text { Operational expenditure (i.e. annual opera- } \\ & \text { tion and maintenance costs) } \\ P \& M & \text { Operation and maintenance costs } \\ R G & \text { Photovoltaics } \\ W S & \text { Resource grade } \\ V R E & \text { Wind speed } \\ S P & \text { Variable renewable energy } \\ & \text { Specific power: Relation between rated } \\ & \text { power and swept area: } \frac{\text { Rated Power }}{\text { Swept Area }}\left[\mathrm{W} \mathrm{m}^{2}\right]\end{array}$

to be lighter (since it does not need to be able to operate above wind speeds of $13 \mathrm{~m} / \mathrm{s}$ ).

While the main advantage of such technology is that it generates significant amounts of electricity at low wind speeds, it comes at a cost. In order to extract more power from lower wind speeds, the rotor of the turbine needs to increase in size while keeping the rated power constant. This ratio of power and rotor size is often expressed as specific power (SP), which is expressed below [7]:

\section{$\frac{\text { Rated Power }}{\text { Swept Area }}\left[\mathrm{W} / \mathrm{m}^{2}\right]$}

In order to extract more power from lower wind speeds, specific power needs to be lowered. The reasoning behind this can be seen in the simple equation below showing that the power in the wind is proportional to the rotor area and WS [8].

$P_{\text {wind }} \approx \frac{1}{2} \rho A_{\text {rotor }} V_{\text {wind }}^{3}$

In order to produce more wind power $\left(P_{\text {wind }}\right)$ at lower WS $\left(V_{\text {wind }}\right)$, the area of the rotor $\left(A_{\text {rotor }}\right)$ needs to be increased. The increased rotor size and thus decreased SP will lead to an increased cost of the turbine, as the blades of the turbine need to increase in length and the mechanical load levels on the different components will increase, all the while maintaining the same power capacity.

While the benefits of LW technology could be dramatic, there will always be a point where the costs outweigh the benefits. This is the key subject in an ongoing LW project [6], which the work presented in this paper is a part of. In the LW project, there is parallel work exploring this LW technology and turbine concept which could be quite different from conventional wind turbine technology. To accelerate this LW turbine concept exploration, the target SP was set to a very low $100 \mathrm{~W} / \mathrm{m}^{2}$. So far, a 3.4 MW LW reference turbine with a $208 \mathrm{~m}$ rotor diameter has been developed and presented [6]. A unique feature of this turbine is a very low cut-out speed of $13 \mathrm{~m} / \mathrm{s}$. The reasoning behind this is twofold; (1) not to contribute to excess wind production at high wind speeds and (2) reduce load and thus cost of the turbine by avoiding operation at high wind speeds.

This paper attempts to identify at what price point the above 3.4 MW $100 \mathrm{~W} / \mathrm{m}^{2} \mathrm{LW}$ turbine would become competitive, as well as investigate how energy system flexibility impacts that price point. Identifying this price point could help wind turbine developers determine whether or not LW technology, such as the $3.4 \mathrm{MW} 100 \mathrm{~W} / \mathrm{m}^{2} \mathrm{LW}$ turbine modelled in this paper, is a viable endeavor. In addition, the potential for LW technology reducing the need for increased system flexibility is analysed, as well as the potential for increased revenue due to both higher capacity factor and generation during low wind speeds when electricity prices can be higher.

\subsection{Literature review and contribution}

Over the past decade, there has been a clear trend in wind turbine technology, which is that SP is falling while hub heights and capacity factors (CF) are increasing, shown in these technical reports [7,9]. That being said, the average SP of new wind turbine installations in 2016 in Northern Europe was still around $300 \mathrm{~W} / \mathrm{m}^{2}$ [10].

Andrew Mills and Ryan Wiser from Lawrence Berkeley National Laboratory have done a number of studies on the economic value of wind, looking into different strategies to increase economic value of wind (and other VRE) at higher VRE penetration rates, such as varying geographic location, real-time pricing, and technology diversity [1114]. Other studies have shown that lowering the specific power of wind turbines can both increase their market value and reduce costs on the system, since they produce energy at times other wind turbines do not, making them "system-friendly" turbines [15-17]. In many of these studies, the term wind value factor is used to describe the phenomenon where increasing wind penetration leads to lower electricity prices during high wind ours, whereas in this paper electricity price is compared to either wind speed or wind capacity factor to describe it.

There have also been studies that have looked specifically at how low specific power turbines compare to conventional turbines using the Balmorel energy system model (which is used in this paper as well), with the turbines modelled having specific powers $\left(\mathrm{W} / \mathrm{m}^{2}\right)$ of 400 , $325,300,250,200$, and 175 [5,18]. In these specific Balmorel studies, low SP turbines have been modelled in competition with other energy technologies, but not competing against other wind turbine models. What all these studies show is that low SP turbines can increase the value of wind, better utilize the transmission system, lower forecast error, and could lead to cheaper financing (due to having higher P99 and P50 than traditional turbines) [14]. These studies have similar methodologies, where they either implement fixed amounts of lower SP turbines into their models and analysing the changes, or they analyse the marginal addition of low SP turbines and compare them to the marginal addition of traditional turbines. In addition, there is no sensitivity analysis on the CapEx of these low SP turbines, with one exception being the recent work from Mills et al. [14], which conducts a sensitivity analysis with low SP turbine price markups of $16 \%$ and $32 \%$ over traditional turbines.

However, this paper takes a different approach to analysing LW technology compared to previous studies, where here LW technology is being modelled endogenously, in competition with conventional turbines (and all other generation technologies), and analysed at more price points. In addition, the impact of the energy system flexibility on LW technology is also being investigated (not just the other way around). Furthermore, this study models further into the future than previous studies, and observes expected revenues of wind technologies in the future electricity market of Northern and Central Europe. Lastly, the LW technology being modelled here has a low cut-out WS of $13 \mathrm{~m} / \mathrm{s}$, which is unique to this study and is compared to an identical turbine with a more conventional cut-out WS of $25 \mathrm{~m} / \mathrm{s}$. This comparison is done to analyse the opportunity cost of reducing the cut-out WS.

\section{Methodology}

This section describes the LW technology in question as well as the methodologies applied in terms of wake modelling for obtaining plantlevel power curves, the CorRES model for simulating VRE generation time series, and the energy Balmorel system model. 
Table 1

IEA 3.4 MW reference onshore turbine vs LW-13 [6]

\begin{tabular}{lll} 
& IEA 3.4 MW [21] & LW-13 [6] \\
\hline Power rating & $3.4 \mathrm{MW}$ & \\
Wind regime & IEC Class 3A & IEC Class 3B \\
Control & Variable speed collective pitch \\
Cut-in WS & $4 \mathrm{~m} / \mathrm{s}$ & $2 \mathrm{~m} / \mathrm{s}$ \\
Cut-out WS & $25 \mathrm{~m} / \mathrm{s}$ & $13 \mathrm{~m} / \mathrm{s}$ \\
Rated WS & $9.8 \mathrm{~m} / \mathrm{s}$ & $8 \mathrm{~m} / \mathrm{s}$ \\
Rotor Dia & $130 \mathrm{~m}$ & $208 \mathrm{~m}$ \\
Hub height & $110 \mathrm{~m}$ & $127.5 \mathrm{~m}$ \\
Drivetrain & Medium speed, Multiple-stage gearbox \\
Min rotor speed & $3.8 \mathrm{rpm}$ & $1.92 \mathrm{rpm}$ \\
Max rotor speed & $11.75 \mathrm{rpm}$ & $7.3 \mathrm{rpm}$ \\
Max tip speed & $80 \mathrm{~m} / \mathrm{s}$ & $80 \mathrm{~m} / \mathrm{s}$ \\
Blade length & $63 \mathrm{~m}$ & $102 \mathrm{~m}$ \\
Blade mass & $16,441 \mathrm{~kg}$ & $31,652 \mathrm{~kg}$ \\
Specific power & $256 \mathrm{~W} / \mathrm{m}^{2}$ & $100 \mathrm{~W} / \mathrm{m}^{2}$ \\
AEP ${ }^{\mathrm{a}}$ (V=6.5, k=2.4) & $11.754 \mathrm{GWh}$ & $17.131 \mathrm{GWh}$ \\
\hline
\end{tabular}

${ }^{\mathrm{a} A n n u a l}$ energy production.

\subsection{The $100 \mathrm{~W} / \mathrm{m}^{2}$ LowWind turbine}

The LW technology used in this paper is truly unique, both in terms of how low the SP is $\left(100 \mathrm{~W} / \mathrm{m}^{2}\right)$ and in terms of low cutout WS of $13 \mathrm{~m} / \mathrm{s}$. The reason a $13 \mathrm{~m} / \mathrm{s}$ cut-out WS was chosen is because conventional turbines reach their rated power around that WS, and one of the main purposes of the LW-13 is to avoid adding to overgeneration during high wind hours. By turning off while the conventional turbines in the system reach their rated power, the LW13 does not add to the magnitude of overgeneration. The impact that both of these specifications have cannot be understated. In Table 1, the difference between a conventional turbine and the LW turbine (named LW-13) is shown. While the calculated blade mass of the LW-13 is almost double the blade mass of the IEA 3.4 MW at $31.6 \mathrm{t}$, it is very light for a $102 \mathrm{~m}$ blade. For comparison, a $100 \mathrm{~m}$ blade developed from Sandia National Laboratories has a blade mass of $50 \mathrm{t}$ based on estimates found in [19]. This could mean that the LW-13 could have a blade mass that is up to $33 \%$ lighter than a conventional turbine of the same rotor diameter, which could lead to significant cost decreases. For example, for onshore turbines, the blades alone make up roughly $18 \%-19 \%$ of the total cost of a turbine, meaning a $33 \%$ drop in material costs of the blade could lead to significant savings [20]. Furthermore, the mass of the blades likely has an impact of the cost of the rest of the turbine, meaning there could be savings in the nacelle and tower as well.

\subsection{Wake modelling}

Detailed wake modelling is carried out in order to include realistic wake losses in the plant performance of the different turbines. Reference wind plant layouts are designed for each turbine studied, all the reference plants have approximately the same rated power (51 MW) and the same land use in order to keep the land costs constant in the different market simulations (land use diameter constraint of 3.37 $\mathrm{km}$ ); this means that the number of turbines and the turbine spacing is different in each reference plant, but the power density remains the same (5.6 MW/ $\mathrm{km}^{2}$ ), enabling fair comparison between turbines. However, this equal power density assumption leads to higher wake losses for the turbines with larger rotor diameters, as they are spaced fewer rotor diameters apart.

Wake modelling is performed using $\kappa-\epsilon-f_{p}$ actuator disk computational fluid dynamics (CFD) wake model [22], with a generic plant layout designed for each turbine technology as described in the previous paragraph. The wake model is executed for wind speeds between 4-12 [m/s] for varying wind directions in 5 degrees steps, a neutral boundary layer wind speed profile with turbulence intensity of $10 \%$ at hub height is used as the inflow conditions. Since the plants will be sited all over Europe, the plant power curve is obtained by taking the lowest $25 \%$ quantile power over the wind directions, this provides a conservative estimation of wake losses independently of the wind rose on each location in Europe.

\subsection{VRE time series generation using CorRES}

VRE time series are generated using the CorRES model [23]. CorRES is based on tens of years of pan-European meteorological data, with both the spatial and temporal correlations in VRE generation modelled [24,25]. The plant-level power curves resulting from wake modelling are used to transform wind speeds obtained at hub height to generation data. Hourly resolution is used for the simulation output, 2009 to 2019 simulated. The weather modelling over all Europe is done with WRF downscaling of the ERA-Interim reanalysis, which produces a wind speed time-series in each location in Europe within $10 \times 10 \mathrm{~km}$ at multiple heights $[23,24]$. The plant-level power curves are applied using this hourly weather data, using interpolation to hub height at each plant location. In order to create accurate wind generation time series for each region in the energy system, 18,776 evenly spaced locations across Northern Europe were used, and each turbine technology (eight in total) was evaluated at each location. All locations in each region were then aggregated into resource grades, described in the next subsection.

\subsection{Hourly wind farm aggregation via resource grades}

Each region was then split into three resource grades to model the changing CFs when more and more wind is installed in a region. Each region in the model is split into three onshore wind areas, resource grade A (RG A), resource grade B (RG B), and resource grade C (RG C). RG A considers the top $10 \%$ of locations with highest mean wind speeds. RG B considers the locations with $10 \%$ to $50 \%$ highest mean wind speeds, and RG C considers the lowest mean wind speed locations (bottom 50\%). Each wind technology is considered for each RG, so in the end $8 \times 3$ time series are extracted from CorRES for each region, and then used as inputs to the energy system model. Maps of these resource grades can be found in Appendix A.

\subsection{Energy system modelling using balmorel}

To model Northern and Central Europe's energy system, the Balmorel energy system model was used. Balmorel is a partial equilibrium model, which assumes perfect competition, that is used to analyse the heat and power sector [26]. It is an open source tool that is built in the GAMS modelling language [27]. In this study, Balmorel is used to optimize Northern and Central Europe's energy systems (electricity, heat, and transport) from a socioeconomic perspective by minimizing the total cost of the system over all years, subject to a large number of constraints including but not limited to generation constraints, storage constraints, transmission constraints, and environmental constraints. Balmorel is often used to optimize future capacity development (at limited time resolutions [28]) as well as more detailed day-ahead simulations [29]. In this paper, a capacity development optimization was run with a 10-year rolling horizon with limited foresight of two years, meaning the model has knowledge of the current year it is optimizing and the next year it is optimizing. For example in the 2025 optimization, the model knows the costs of generation technologies for 2025 and 2035, but not 2045. Lastly, perfect competition is assumed throughout the model.

Before starting the capacity development optimization, all timeseries data is scaled to ensure the data in the hours chosen are a good representation of the entire data set using a probability integral transformation to match the probability distributions of the full year of data (described in detail here [30]. This is done because only $408 \mathrm{~h} \mathrm{(4.7 \%}$ 


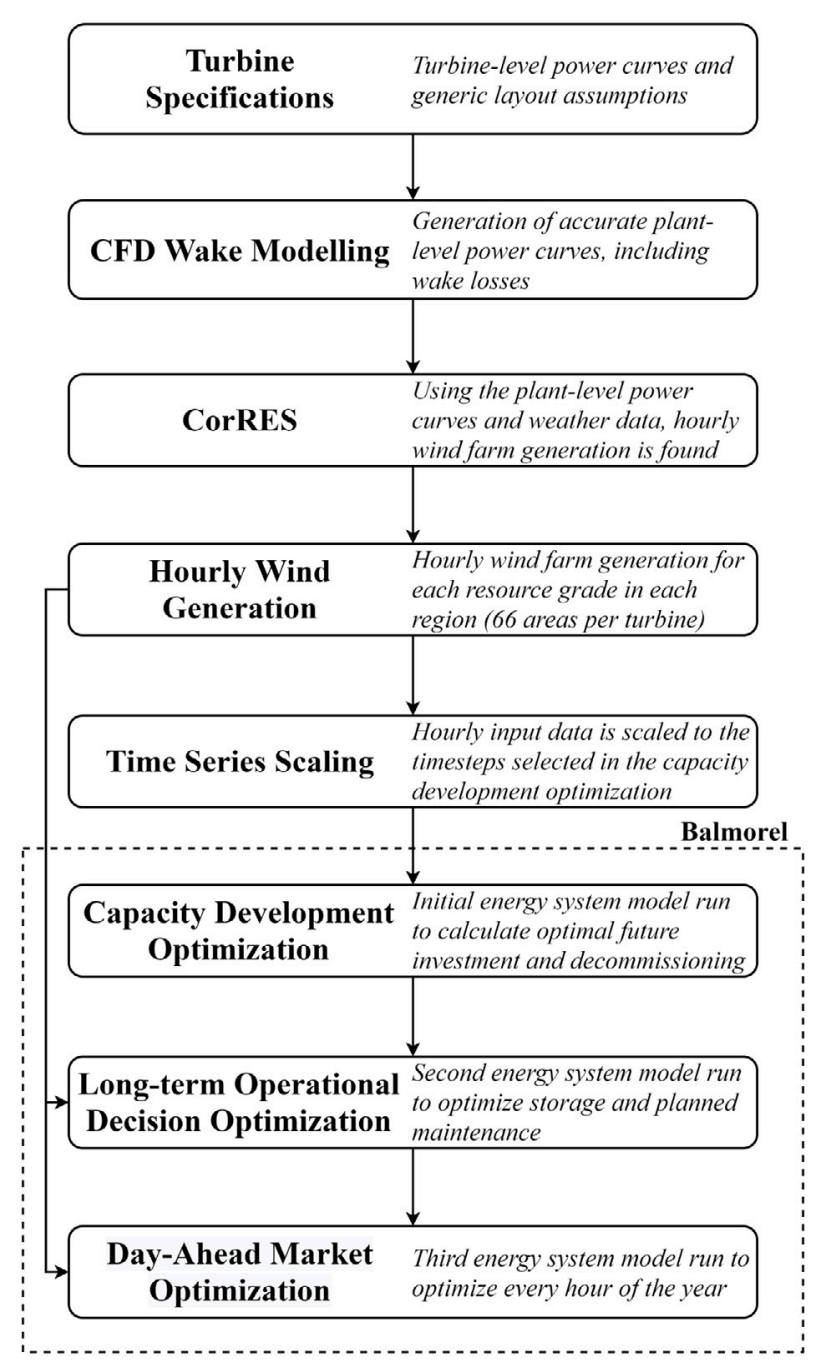

Fig. 1. Visual representation of the methodology used in this study.

of the year) across the year optimized in this run for computational tractability. The investment results from this run become inputs to a higher time resolution long-term operational decision optimization run, where storage and planned maintenance are optimized and every 4th hour of the year is run (25\% of the year). The storage and dispatch results (and the investment results from the first run) are inputted to a day-ahead market optimization run, where every hour of the year. The capacity development optimization and long-term operational decision optimization are run with perfect foresight of the time steps included, whereas the day-ahead market optimization simulates the operation of the day-ahead market, and hence, it is run day-by-day, linking the results from the previous day to the next day.

This section describes the LW technology in question as well as the methodologies applied in terms of wake modelling for obtaining plant-level power curves, the CorRES model for simulating VRE generation time series, and the Balmorel energy system model. A visual representation of the methodology used in this paper can be seen in Fig. 1.

\section{Input data for energy system model}

In order to model Northern and Central Europe's energy system, a large number of inputs are added to the Balmorel energy system model. These inputs include the cost of energy technologies, $\mathrm{CO}_{2}$ taxes, fuel prices, future energy demand, and fuel potentials. All cost inputs
Table 2

System-wide annual electricity demand (TWh)

\begin{tabular}{llll}
\hline Year & 2025 & 2035 & 2045 \\
\hline Exogenous demand & 1,345 & 1,057 & 1,118 \\
EV demand & 34 & 318 & 870 \\
Synthetic fuel demand & 0 & 290 & 770 \\
Electricity-to-heat & 664 & 823 & 887 \\
\hline Total demand & $\mathbf{2 0 4 3}$ & $\mathbf{2 4 8 8}$ & $\mathbf{3 6 4 5}$ \\
\hline
\end{tabular}

Table 3

$\mathrm{CO}_{2}$ price in all countries [32].

\begin{tabular}{llll}
\hline Year & 2025 & 2035 & 2045 \\
\hline$€ / \mathrm{tCO}_{2}$ & 29.72 & 90.19 & 120.25 \\
\hline
\end{tabular}

presented in this paper are in 2012 euros, and the outputs of the model are in 2016 euros. An overview of the model and data used in this paper can be found here [31], although a few updates have been made for the purpose this paper, the main addition being the addition of six conventional onshore wind turbines and the LW turbines. Other data updates include energy efficiency assumptions and updated national onshore wind potentials.

It is worth mentioning that it has been assumed that Northern and Central Europe's energy system will be heavily decarbonized by 2050 , with all road transport, shipping, and aviation being electrified by 2050. Likewise, nearly all heat demand is also electrified by 2050 , which occurs endogenously. The impact these assumptions have on electricity demand can be seen in Table 2 . Together, these inputs result in a large increase to electricity demand in the future and a sector coupled energy system that has many measures of cheap flexibility, such as flexible demand from synthetic fuel production, and heat storage in both district heating areas, industry, and residential heating areas. Furthermore, high $\mathrm{CO}_{2}$ taxes are assumed to take effect in the future (seen in Table 3), which signals the model to invest more in VRE generation. More details regarding input data can be found in Appendix A.

It is also worth mentioning that, although future synthetic fuel demand is present in the model (assuming all shipping and aviation will be powered by synthetic fuel), the model used here does not allow for hydrogen storage investment, simply because in prior uses of the model there was no hydrogen storage investment, thus it was removed to decrease complexity of the model. A more detailed explanation can be found in Appendix A.

\subsection{Turbine types, hub heights, and costs}

A selection of traditional turbine types were added to the model to create realistic competition for the LW-13. An overview of them is given in Table 4. The three types cover specific powers from 198 to $335 \mathrm{~W} / \mathrm{m}^{2}$, which is assumed to represent the selection of turbine types usually considered in Europe. Two hub heights, $100 \mathrm{~m}$ and $150 \mathrm{~m}$, are considered for each rotor to reach six traditional wind technologies in total. For the LW turbines, a hub height of $127.5 \mathrm{~m}$ is used as this is the hub height of the LW turbine described in [6]. It should be noted that even with this modest tower height of the LW turbine, the maximum tip height is $231.5 \mathrm{~m}$, due to the extremely long blades (102 m blade length), is above the maximum tip height of $221 \mathrm{~m}$ of the conventional SP198-HH150 turbine. The number of turbines and minimum spacing in rotor diameters of the final plant are also presented in Table 4.

Along with the time series information generated from CorRES, the costs of each new turbine must also be added. To calculate the CapEx of each turbine, NREL's Wind-Plant Integrated System Design \& Engineering Model (WISDEM) was used. WISDEM is an open-source model built on NASA's OpenMDAO software, that creates a vertically integrated wind plant from components to operations [33,34]. For 
Table 4

Onshore wind farms modelled in Balmorel.

\begin{tabular}{lllllll}
\hline $\begin{array}{l}\text { Turbine name } \\
\text { (Units) }\end{array}$ & $\begin{array}{l}\text { Rated power } \\
(\mathrm{MW})\end{array}$ & $\begin{array}{l}\text { Rotor diam. } \\
(\mathrm{m})\end{array}$ & $\begin{array}{l}\text { Specific power } \\
\left(\mathrm{W} / \mathrm{m}^{2}\right)\end{array}$ & $\begin{array}{l}\text { Hub height } \\
(\mathrm{m})\end{array}$ & $\begin{array}{l}\text { Turbine number } \\
\text { (turbines) }\end{array}$ & $\begin{array}{l}\text { Min. turbine spacing } \\
\text { (rotor dia.) }\end{array}$ \\
\hline SP335-HH100 & 3.60 & 117 & 335 & 100 & 14 & 7.48 \\
SP335-HH150 & 3.60 & 117 & 335 & 150 & 14 & 7.48 \\
SP277-HH100 & 3.45 & 126 & 277 & 100 & 15 & 6.61 \\
SP277-HH150 & 3.45 & 126 & 277 & 150 & 15 & 6.61 \\
SP198-HH100 & 3.15 & 142 & 198 & 100 & 16 & 5.92 \\
SP198-HH150 & 3.15 & 142 & 198 & 150 & 16 & 5.92 \\
LW-13 & 3.4 & 208 & 100 & 127.5 & 15 & 3.9 \\
\hline
\end{tabular}

Table 5

Wind turbine CapEx in each decade $(\mathrm{M} € / \mathrm{MW})$.

\begin{tabular}{llll}
\hline Turbine & 2025 & 2035 & 2045 \\
\hline SP335-HH100 & 1.14 & 1.03 & 0.95 \\
SP335-HH150 & 1.49 & 1.34 & 1.23 \\
SP277-HH100 & 1.25 & 1.12 & 1.03 \\
SP277-HH150 & 1.60 & 1.44 & 1.33 \\
SP198-HH100 & 1.52 & 1.37 & 1.26 \\
SP198-HH150 & 1.91 & 1.72 & 1.58 \\
SP198-HH127.5 & 1.71 & 1.54 & 1.42 \\
LW-13 $^{\mathrm{b}}$ & $2.19-2.57$ & $1.97-2.32$ & $1.82-2.13$ \\
\hline
\end{tabular}

a This turbine is only used as a cost reference; it is not an investment option in the model.

${ }^{\mathrm{b}} \mathrm{LW}$ CapEx numbers have a range because they are part of the sensitivity analysis conducted in this paper.

this paper, the Turbine_CostsSE module within WISDEM was used to calculate the cost of each conventional wind turbine in this model. Given a hub height, rotor diameter, and power rating, this module can estimate the CapEx of each wind turbine. With the given turbine CapEx, the balance of system (BOS) costs and financing costs were estimated using assumptions from [20], where onshore turbines make up $68.8 \%$ of the total CapEx of an onshore wind farm. The equation below describes how CapEx was calculated for the conventional turbines.

CapEx $x_{\text {wind farm }}=\frac{\text { Turbine CapEx from WISDEM }}{68.8 \%}$

Using this equation, a realistic cost spread is generation between the six convention turbines. However, since all other technology costs in the model come from the Danish Energy Agency's (DEA) technology catalogue [35], the results from WISDEM's Turbine_CostsSE module, which considers the US market by default, were scaled such that they are aligned with the onshore wind cost data from DEA for the turbine type best comparable between the WISDEM and DEA data. This scaling resulted in multiplying the results from WISDEM by a factor of 1.296. Furthermore, OpEx costs (both fixed and variable) are the same for each turbine and come from [35], and can be found in Appendix A. The full CapEx results are shown in Table 5. It is assumed future onshore wind CapEx/MW will decrease by $10 \%$ between 2025 to 2035, and $8 \%$ between 2035 and 2045 [36].

\subsection{Plant-level power curves}

Wake modelling is applied to obtain plant-level power curves for each conventional turbine and for the two LW turbines. The 5.61 $\mathrm{MW} / \mathrm{km}^{2}$ is kept constant for all the plants for each turbine technology to reach the same area usage per MW installed. This means that the LW technology modelled in this paper has a tighter turbine spacing to enable a fair comparison to the other turbines in terms of land cost per MW installed. Note that turbine spacing can be seen in the last column of Table 4 (spacing is given in rotor diameters), a variable which has a large impact on the predicted wake losses. Although this process does not represent optimized plant layouts for a given location, it provides simple comparison of the technologies as they have the same land use cost. The resulting plant-level power curves are shown in Fig. 2.

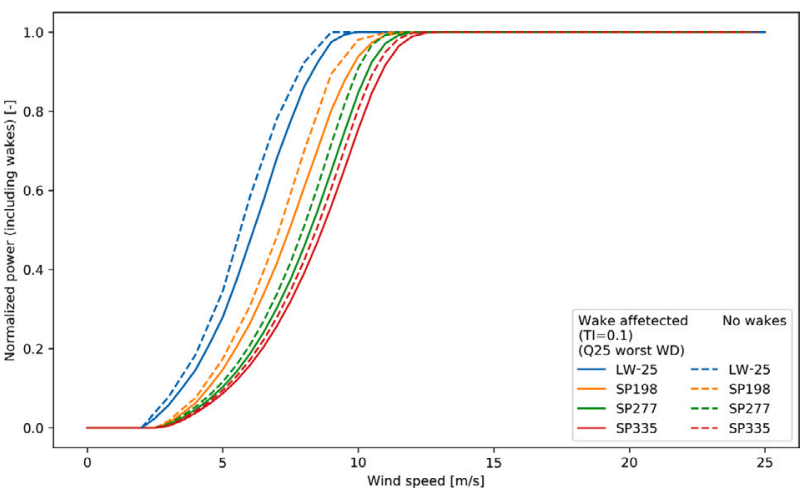

Fig. 2. Turbine-level power curves and resulting plant-level traditional and LW power curves (shutdown not considered).

Modelling turbine spacing in this way leads to two competing effects impacting the performance of the different turbine technologies within a plant: (a) lowering specific power increases the power curve, while (b) lowering turbine spacing increases wake losses. This can be seen in the plant power curve comparison in Fig. 2

As expected, the turbines with lower specific power have higher generation at lower wind speeds. The wake losses are slightly larger for plants that use lower specific power turbine, this is caused by the tighter layouts obtained with larger rotors when keeping the land use constraint.

\subsection{The $L W-13$ and $L W-25$ turbines}

The two studied low wind types, LW-13 and LW-25, differ in terms of the cut-out WS. As shown in Fig. 3, the LW-13 starts to reduce generation after $12 \mathrm{~m} / \mathrm{s}$ up to $15 \mathrm{~m} / \mathrm{s}$, in order to have a controlled shutdown that will reduce the generation ramp rates from full-power shutdown, with zero production reached at around $16 \mathrm{~m} / \mathrm{s}$, whereas the LW-25 experiences shutdown at around the usual $25 \mathrm{~m} / \mathrm{s}$ cut-off limit. Note that the shutdown is simulated with a hysteresis model presented in [37], in Fig. 3 the dotted lines represent the restart curve, while the actual shutdown operation will depend of the temporal changes in WS.

CorRES simulation results for LW-13 and LW-25 are shown in Fig. 4 for a high wind region. The years 2000 to 2018 are simulated on hourly resolution. It can be seen that in this region, the LW-13 shows significantly lower CF than LW-25. For a low wind region, as shown in Fig. 5, however, the LW-13 shows a similar CF to the LW-25. This highlights the importance of modelling the different technologies in detail for different regions and RGs.

\section{Analysed energy system scenarios}

To reiterate, two of the main purposes of this paper are to analyse at what relative price point the $100 \mathrm{~W} / \mathrm{m}^{2} \mathrm{LW}$ turbine would become competitive relative to conventional turbines as well as how energy system flexibility impacts said price point. For this reason, the 10 scenarios shown in Table 6 were analysed, where both LW CapEx 


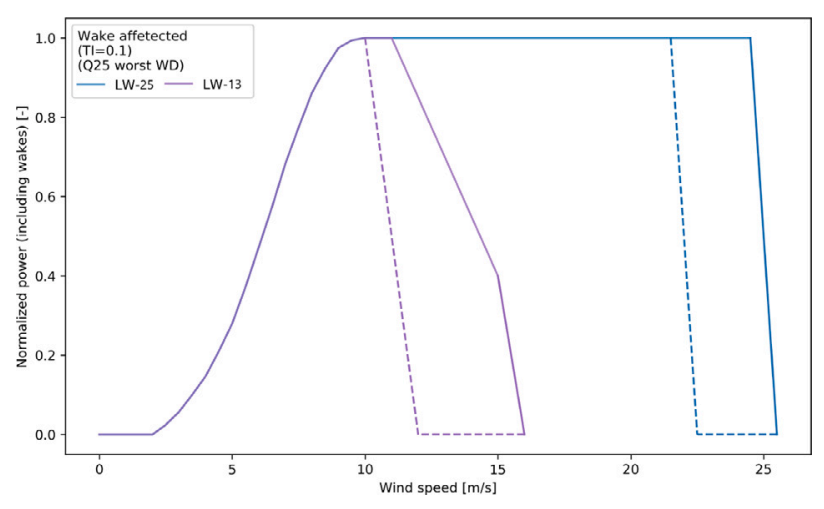

Fig. 3. The LW-13 (purple) and LW-25 (blue) plant power curves, the dotted lines are the restart curve.
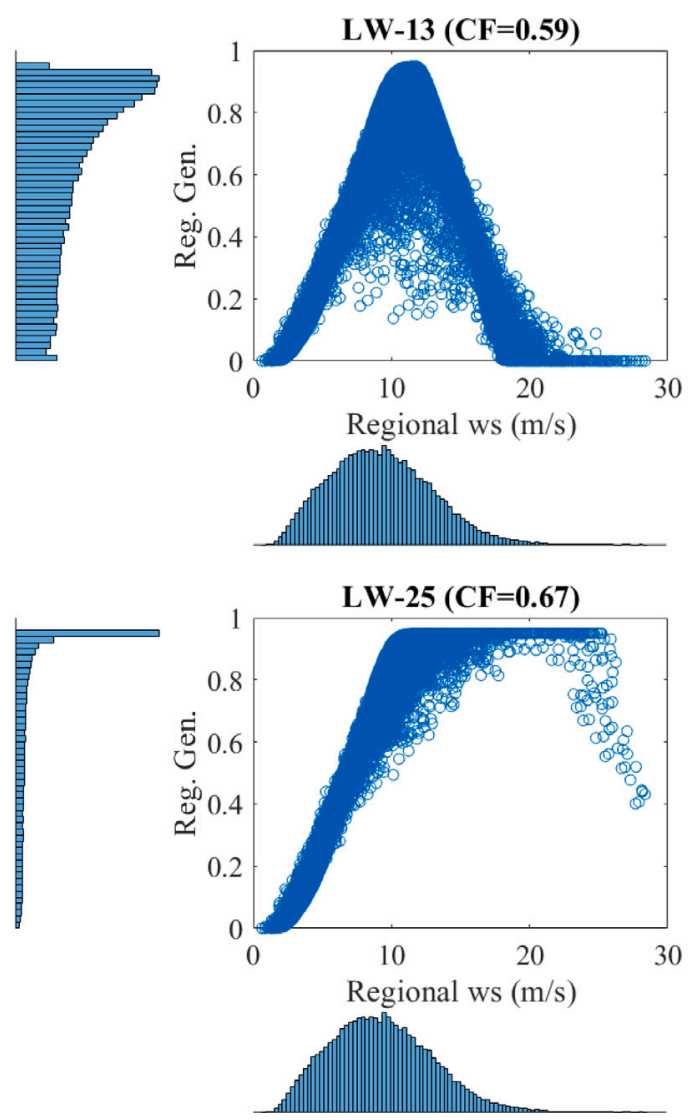

Fig. 4. Regional simulation results for LW-13 and LW-25 in resource grade $A$ in Denmark west.

and energy system flexibility were changed in order to examine at what price point the LW turbine sees investment, how LW investment impacts the energy system, and how decreasing system flexibility (via lowering transmission capacity) impacts LW investment.

In addition to these scenarios, two versions of the LW turbine are analysed in this paper, the LW-13 (with a cut-out speed of $13 \mathrm{~m} / \mathrm{s}$ ), and the LW-25 (with a cut-out speed of $25 \mathrm{~m} / \mathrm{s}$ ), to study the impact of two different cut-out limits on the competitiveness of the LW turbine. Besides the different cut-out WS, the two turbines are identical physically and financially. These two LW types are each analysed in the 10 scenarios shown in Table 6. The purpose of including the LW-25 is to measure the opportunity cost of the LW-13's low cut-out WS.

Five price points are modelled in order to analyse at what price point the LW-13 becomes competitive. These price points have been
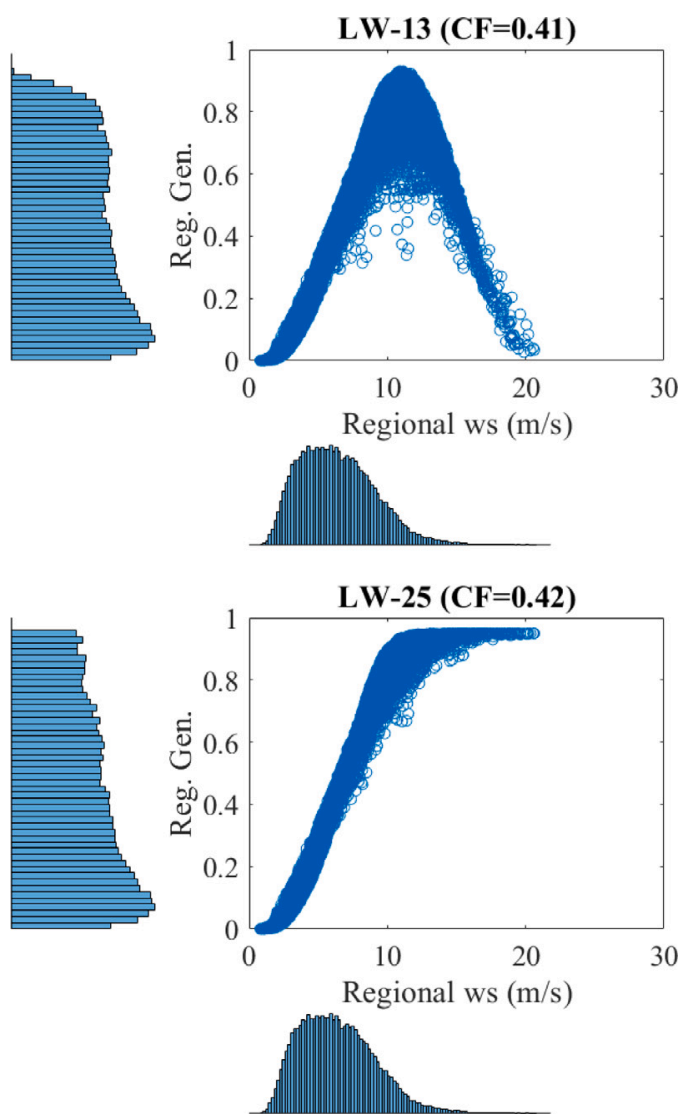

Fig. 5. Regional simulation results for LW-13 and LW-25 in resource grade C in Germany south.

chosen relative to a reference conventional turbine with the same hub height $(127.5 \mathrm{~m})$ as the LW-13, and a smaller rotor $(142 \mathrm{~m}$ vs $208 \mathrm{~m}$ ). Using the same naming scheme used for the other conventional turbines, this reference turbine's name is SP198-HH127.5. The costs for this turbine can be seen in Table 5 . The price points modelled for the LW-13 are between a $+28 \%$ and $+50 \%$ price increase over this reference turbine. The specific price increase points were chosen based on preliminary models runs, where price increases below $+28 \%$ lead to near $100 \%$ LW-13 market share (resulting in a reasonable lower bound), and price increases above 50\% lead to no LW-13 investment (resulting in a reasonable upper bound).

In these scenarios, two different energy system scenarios were modelled, one named BASE and one named NoTrans. The only difference between the two scenarios is that in NoTrans, endogenous transmission capacity investment is disallowed, whereas in the BASE scenario, endogenous transmission investment is allowed. The purpose of modelling these two scenarios is to investigate the impact system flexibility (in this case transmission capacity) has on LW investment. More information about the energy system model assumptions can be found in Appendix A.

\section{Energy system model results}

This section summarizes the findings of this paper. There are a number of key observations, which include finding the price point at which the LW turbines become competitive, examining the impacts the introduction of the LW turbine technology has on the system, and inspecting how the level of the energy system's flexibility impacts the investment in LW turbines. Furthermore, a detailed investigation of potential wind farm revenue in both Western Denmark and Southern Germany is analysed. 
Table 6

Price sensitivity overview in 2025.

\begin{tabular}{lllll}
\hline Scenario name & $\begin{array}{l}\text { Endogenous } \\
\text { transmission } \\
\text { investment? }\end{array}$ & $\begin{array}{l}\text { LW-13/LW-25 } \\
\text { CapEx in 2025 } \\
(\mathrm{M} € / \mathrm{MW})\end{array}$ & $\begin{array}{l}\text { LW-13/LW-25 } \\
\text { CapEx in 2035 } \\
\text { (M€/MW) }\end{array}$ & $\begin{array}{l}\text { LW-13/LW-25 } \\
\text { CapEx in 2045 } \\
\text { (M€/MW) }\end{array}$ \\
\hline BASE (+28\%) & YES & 2.19 & 1.97 & 1.82 \\
BASE (+34\%) & YES & 2.29 & 2.06 & 1.89 \\
BASE (+39\%) & YES & 2.38 & 2.14 & 1.97 \\
BASE (+45\%) & YES & 2.48 & 2.23 & 2.05 \\
BASE (+50\%) & YES & 2.57 & 2.32 & 2.13 \\
NoTrans (+28\%) & NO & 2.19 & 1.97 & 1.82 \\
NoTrans (+34\%) & NO & 2.29 & 2.06 & 1.89 \\
NoTrans (+39\%) & NO & 2.38 & 2.14 & 1.97 \\
NoTrans (+45\%) & NO & 2.48 & 2.23 & 2.05 \\
NoTrans $(+50 \%)$ & NO & 2.57 & 2.32 & 2.13 \\
\hline
\end{tabular}

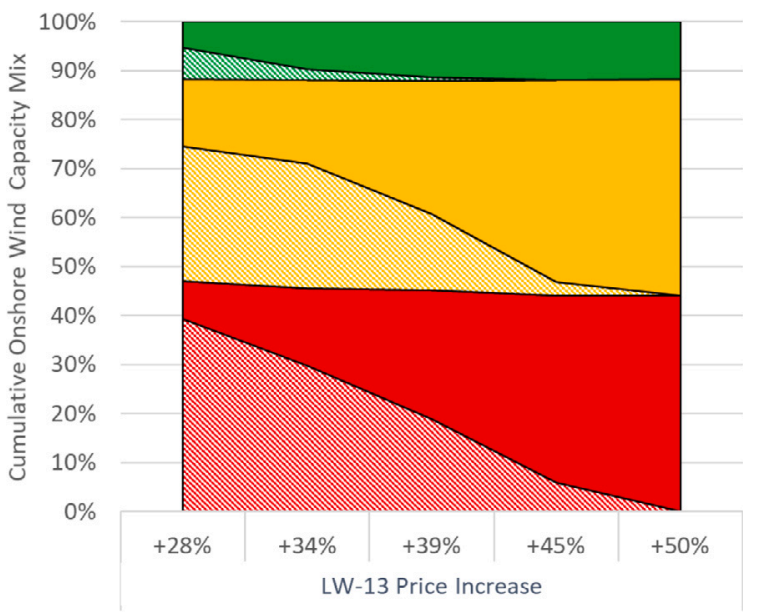

$\square$ RG A - Conventional Onshore

的 A - LW-13 $\square R G$ B - Conventional Onshore $\square R G B-L W-13$ 因 C - LW-13
Fig. 6. Cumulative onshore turbine capacity mix in BASE scenarios in 2045 (13 m/s cut-out).

\subsection{Price point investigation}

In this section, LW-13/LW-25 price is shown in percentages, and reflects the CapEx of the LW turbines in each scenario relative to the SP198-HH127.5 reference turbine, whose costs can be seen in Table 5. The actual cost of the LW turbines in each scenario can be seen in Table 6. Such comparison can help turbine manufacturers in knowing how much more expensive the LW technology can be compared to currently available turbines that are meant for low wind sites.

Fig. 6 shows cumulative LW-13 investment vs cumulative conventional turbine investment in the BASE scenario, in each resource grade, at each price sensitivity ( $+28 \%$ to $+50 \%)$ by 2045 . What is meant by "conventional turbine" in these figures is the onshore turbines shown in Table 4, excluding the LW-13 (they are the turbines that were added to the model to create a fair competition for the LW-13). To be clear, the SP198-HH127.5 is not in the model, it is merely used as a cost reference for the LW-13, since it has the same hub height as the LW-13. In the figures in this subsection, the solid colours represent conventional turbine capacity, and the patterned colours represent LW capacity. In the BASE scenario, the LW-13 begins to see investment in the $+45 \%$ price scenario ( $33 \mathrm{GW}$ ), however it becomes truly disruptive in the $+39 \%$ price scenario ( $133 \mathrm{GW}$ ), where nearly half of all investments in RG B and RG C are in LW-13. What is meant by disruptive is simply seeing over $100 \mathrm{GW}$ of investment. When the cut-out WS is increased to $25 \mathrm{~m} / \mathrm{s}$ in the LW-25, which can be seen in Fig. 7, LW technology becomes disruptive in the $+45 \%$ price scenario. This finding shows that there is value in extending the LW-13's cut-out speed to $25 \mathrm{~m} / \mathrm{s}$. Since

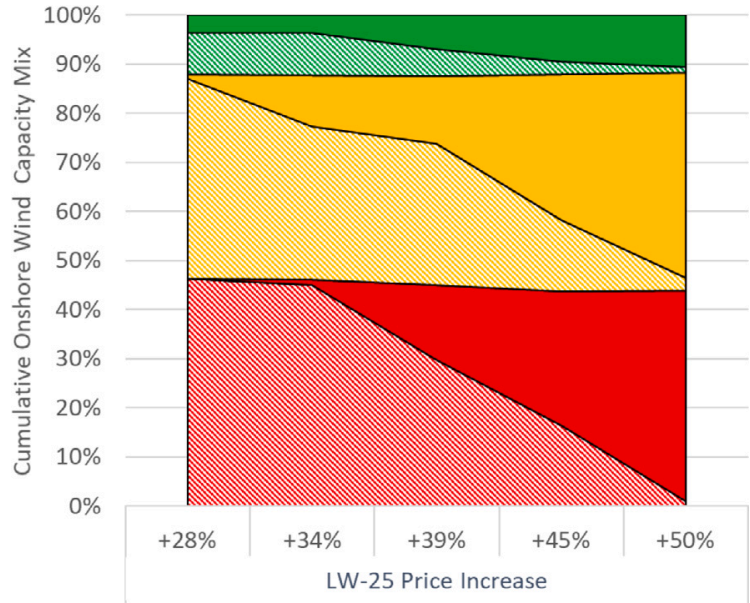

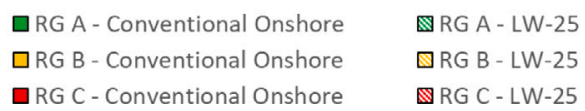

Fig. 7. Cumulative onshore turbine capacity mix in BASE scenarios in $2045(25 \mathrm{~m} / \mathrm{s}$ cut-out).

the LW-25 in the $+45 \%$ scenario saw similar investment levels as the LW-13 did in the $+39 \%$ scenario, there is an indication that the cut-off WS increase could be worth an increase in CapEx of 5\% (0.12 M€/MW in 2025). Analysis of wind farm revenue can be found towards the end of this section, which will add to this analysis of cut-out wind speeds.

Another interesting observation, which can be seen in Fig. 8, is that when the energy system becomes less flexible through disallowing endogenous transmission investment, the LW-13 sees investment in the $+50 \%$ scenario, and becomes disruptive in the $+45 \%$ price scenario. This shows that flexibility of the energy system has a significant impact on LW technology's value to the system.

The conclusion here is that, from an system cost minimization perspective, the LW-13 provides enough value to the system to garner a CapEx that is at the price levels of the $+45 \%$ price scenario $(2.48$ $\mathrm{M} € / \mathrm{MW}$ in 2025), whose cost is shown in Table 5. To reiterate, investments shown in this section are cumulative through 2045, so the cost/MW of each turbine changes in each decade, and therefore relative costs are used to describe LW turbine costs.

\subsection{LW-13's impact on the system}

The impact LW technology has on the system can be seen in a number of ways. One argument for introducing more LW turbines into the energy system is that they are more "system friendly" than traditional turbines, meaning they are cheaper to integrate since they have higher capacity factor [15]. This should lead to a lower need for flexibility in theory, as there are fewer hours of high net load 


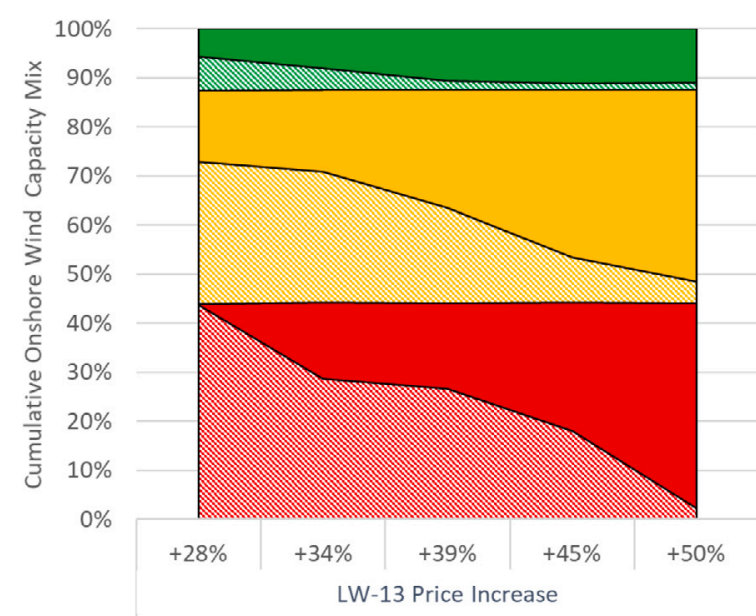

$\square R G$ A - Conventional Onshore

$\mathbb{R G} A-L W-13$ $\square R G$ B - Conventional Onshore $\square R G B-L W-13$ $\square$ RG C - Conventional Onshore

Fig. 8. Cumulative onshore turbine capacity mix in NoTrans scenarios in 2045 (13 m/s cut-out).

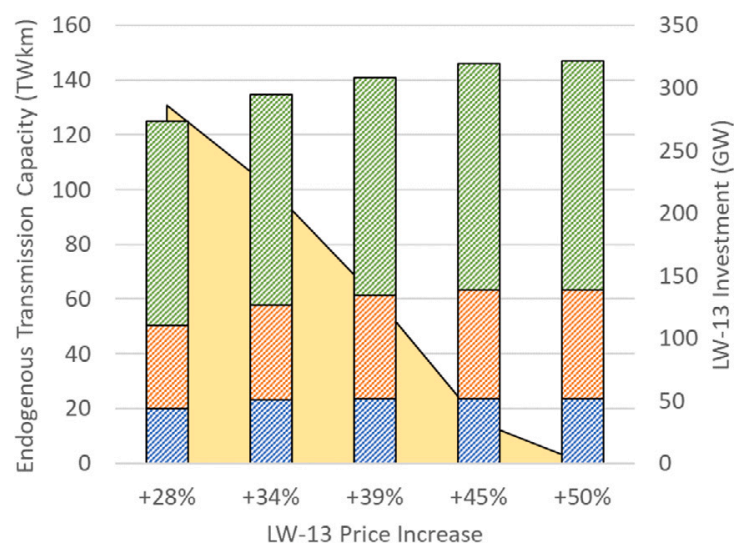

Endogenous Transmission Investment in: 圂 2025 圆2035 目2045 $\square$ LW-13 Investment (Right Axis)

Fig. 9. Cumulative transmission investment in BASE scenario as LW-13 price increase changes.

(net load = electricity demand $-V R E$ generation). This lower need for flexibility can also be seen in the model's results. Looking at Fig. 9, as the LW-13 becomes cheaper in the BASE scenario (left side of the figure), thereby increasing the amount of LW investment, the amount of endogenous transmission investment falls, measured in TWkm. What can be seen by comparing the BASE $(+28 \%)$ scenario to the BASE $(+50 \%)$ scenario is that adding $286 \mathrm{GW}$ of $\mathrm{LW}-13$ to the system by 2045 leads to a reduction of transmission investment by 22 TWkm (a 15\% reduction). For reference, there is $50 \mathrm{TWkm}$ already in the system in 2020. This shows that as more LW turbines are in the energy system and onshore wind $\mathrm{CF}$ increases, the amount of transmission capacity needed falls. It falls because during hours of low VRE generation (when the energy system needs to utilize the transmission the most), there is much more generation from LW turbines than there would be otherwise from conventional turbines, reducing the amount of additional imported MWh needed in low VRE generation areas. In addition, increasing onshore wind CF leads to higher transmission utilization, which also leads to less transmission investment.

The introduction of LW technology also changes investment in other generation technologies. Fig. 10 shows that when LW technology is

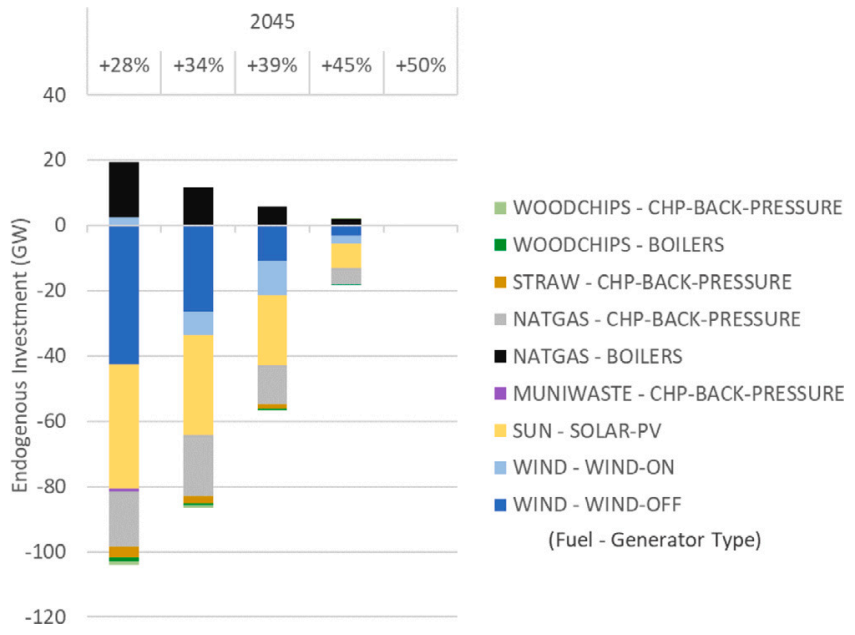

Fig. 10. Change in cumulative generation investment in the BASE scenarios relative to BASE (+50\%), which has no LW investment.

cheap (left side of the figure), it replaces generation from offshore wind ( $-42 \mathrm{GW})$, solar $(-38 \mathrm{GW})$, and natural gas CHP ( $-17 \mathrm{GW})$. What is interesting here is that the amount of onshore wind capacity remains the same in the different price scenarios (only the onshore wind technology mix changes), because onshore wind capacity limits are met in the regions with high demand electricity demand. However, up to $80 \mathrm{GW}$ of other VRE generation is avoided by 2045 as LW investment increases. There is also a shift from natural gas fired CHP plants to natural gas fired boilers, occurring due to less district heating expansion when more LW technology is in the system, which is caused by a lower need for flexibility (which DH systems can provide).

Where LW technology is being installed is another relevant finding. In Fig. 11 it can be seen that most investment occurs in Germany and Poland. In general, LW is invested in the regions with lower wind speeds, e.g. Denmark and the UK do not see any LW investments while Germany and Poland see large investment. What is also interesting is the amount of LW-13 investment seen in Lithuania in 2045 (10.7 GW), which is substantial when compared the country's total electricity generation capacity (22.2 GW in 2045). There is one outlier in Fig. 11, which is Poland. What is happening here is the model decided to build $22 \%$ of the synthetic fuel production in Poland, and another $14 \%$ in the Baltic counties by 2045 . This large demand (270 TWh in 2045) in Poland and the Baltics lead to large onshore investment in these countries. This makes sense because onshore wind is the cheapest form of clean energy, and both Poland and the Baltic states have lower population density than Central Europe, meaning there is less exogenous energy demand and plenty of space for wind farms. It is also interesting to point out that there is little LW investment in 2025. The large amount of investment in later decades is primarily due to higher electricity demand as well as higher carbon taxes.

\subsection{Impacts of limiting transmission investment}

Another goal of this paper is to examine how grid flexibility (namely eliminating endogenous transmission investment) impacts LW turbine investment. While we have already seen how it impacts turbine market share in 2045, we have not looked at how system flexibility impacts other years, nor its impact on installed capacity of wind. From Fig. 12, we can see how the various system scenarios impact wind technology investment. One takeaway is that, in the NoTrans scenario, there is much more investment in LW than in the BASE. It also leads to earlier investment in LW technology, already seeing significant investment in 2025. These results are significant because they provide evidence that LW technology is more valuable in energy systems with less flexibility, 


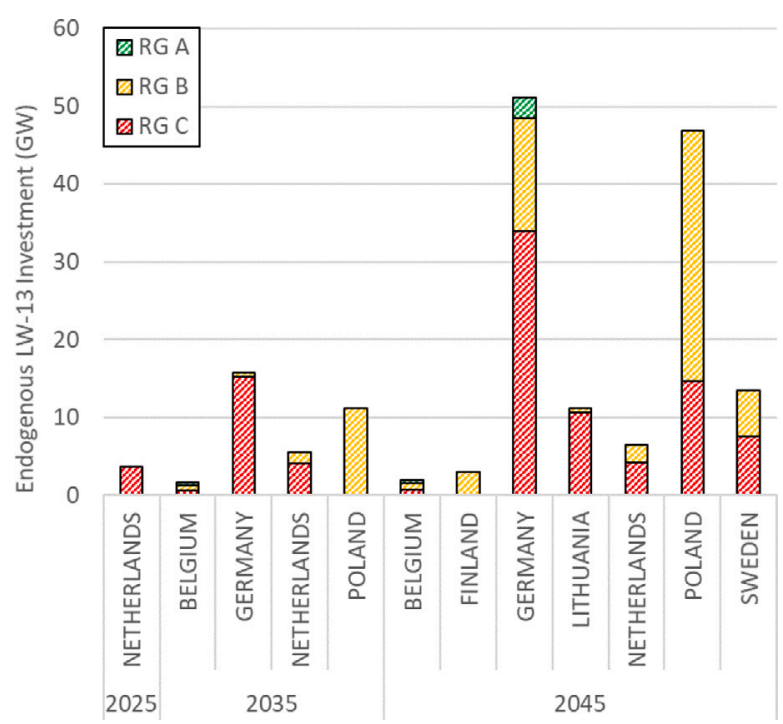

Fig. 11. Cumulative LW-13 investment in BASE scenario at $39 \%$ price increase.

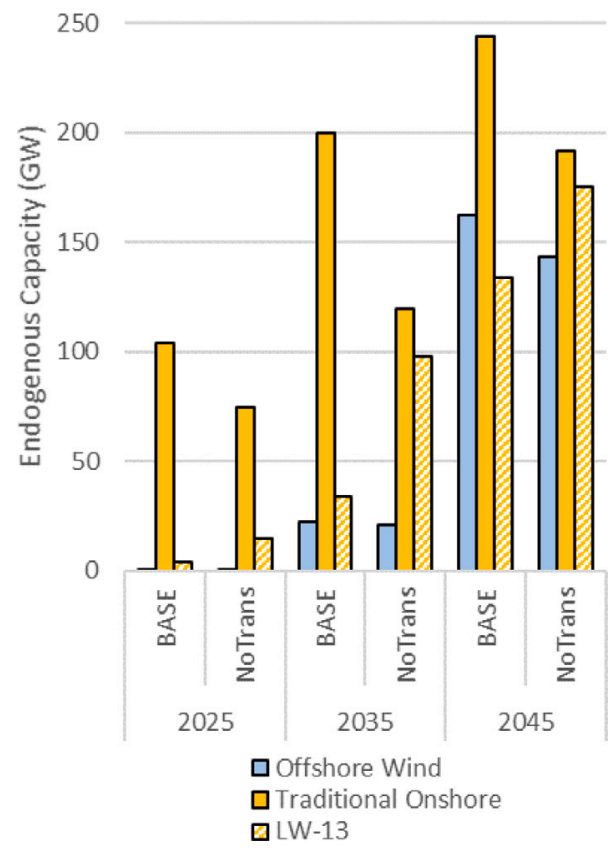

Fig. 12. Cumulative wind technology investment at $39 \%$ price increase in both grid scenarios.

and also indicate that there could be an earlier market opportunity as today's system is much less flexible than the system modelled in this paper.

\subsection{Hourly analysis}

In this section, the results from higher time resolution model runs are investigated. The analysis here looks at how LW technology influences electricity prices as well as how much revenue LW technology could make compared to traditional turbines. In order to conduct this analysis, further model runs were performed with the results from the capacity optimization discussed earlier in this section as inputs, allowing for higher time resolution.

There are a number of takeaways from the price duration curve of the BASE $(+50 \%)$ scenario (with no LW technology investment),

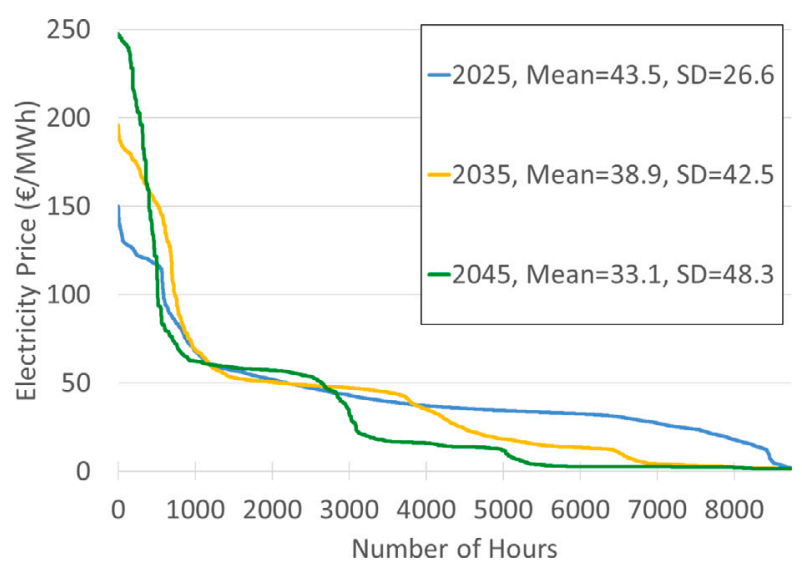

Fig. 13. Price duration curve in BASE $(+50 \%)$ scenario.

which can be seen in Fig. 13. As we get closer to 2050, there are more and more hours of near-zero electricity prices as well as an increase in both hours of high electricity price and price range. This is caused by increasing amounts of zero marginal cost renewable energy in the system that is installed due to increasing electricity demand and carbon taxes. The near zero prices usually occur when all electricity demand is covered by wind and solar. What often happens during these hours is overgeneration, where wind and solar farm curtailment occurs due to electricity generation being higher than electricity demand. Since the highest marginal cost generator sets the price, and all generation is met by zero marginal cost VRE generation, electricity prices fall to zero more often as VRE share increases. This graphic also shows the "selfcannibalization" effect mentioned in the introduction of this paper, showing that in 2045 , during $1 / 3$ of all hours, electricity price is near zero.

Now that a baseline has been established for each decade, we can look at how increasing amounts of LW technology impact electricity prices, specifically in 2045. Additionally, it is relevant to also observe how limiting transmission investment impacts future electricity prices. The impact of both the introduction of LW technology and limiting transmission investment can be seen in Fig. 14, which shows the price duration curve in 2045, both as LW investment varies (by varying the price of LW from $+28 \%$ to $+50 \%$ ) as well as when endogenous transmission investment is disallowed (in the NoTrans scenario). The electricity prices in both Fig. 13 and Fig. 14 are aggregated electricity prices, weighted by electricity demand of each region in 2045. For example France has a much higher impact on the aggregated electricity price than Estonia, since France has a much higher electricity demand.

What can be seen in Fig. 14 is that higher levels of LW investment (remember, the higher the price increase, the lower the investment) lead to less hours of very low electricity prices. Specifically, when comparing the BASE $+28 \%$ scenario to the BASE $+50 \%$ scenario, there are 304 fewer hours of near-zero electricity prices in the $+28 \%$ price scenario (near-zero meaning below $5 € / \mathrm{MWh}$ ). This make sense, because with higher levels of LW investment, there are less turbines in the system that produce energy at high wind speeds (when the system is saturated by wind energy). In other words, the wind production becomes more spread out across wind speeds, so that during high wind events, less areas are producing more electricity than they can use, leading to less hours with zero-cost electricity and more electricity being produced at higher prices. More LW-13 investment also lead to higher average electricity prices, increasing from $33.1 € / \mathrm{MWh}$ in the BASE $(+50 \%)$ to $39.8 € / \mathrm{MWh}$ in the BASE $(+28 \%)$ scenario. The figure also shows that the number of hours of very high prices increases as LW investment increases. This occurs because more LW-13 investment leads to less CHP investment, which means the system relies on peaker plants during more hours of the year. 


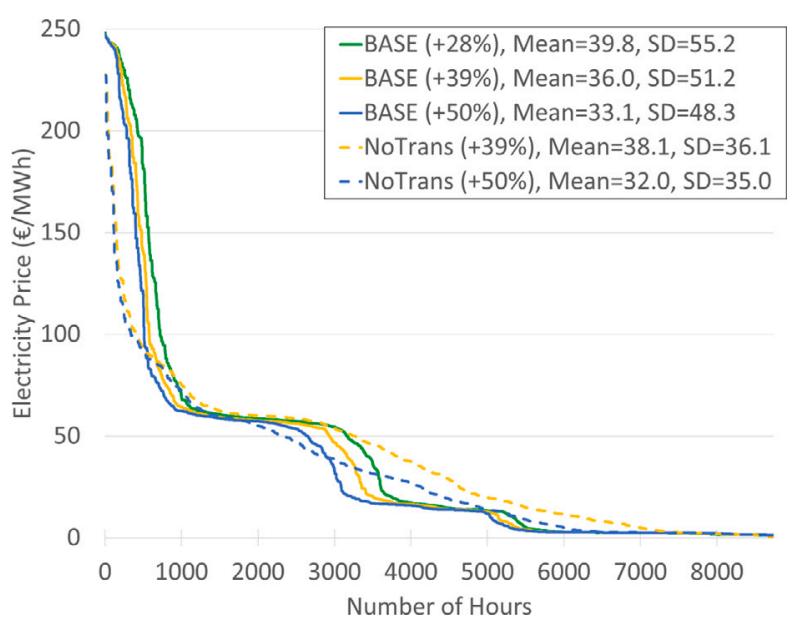

Fig. 14. Price duration curve in 2045 across various scenarios.

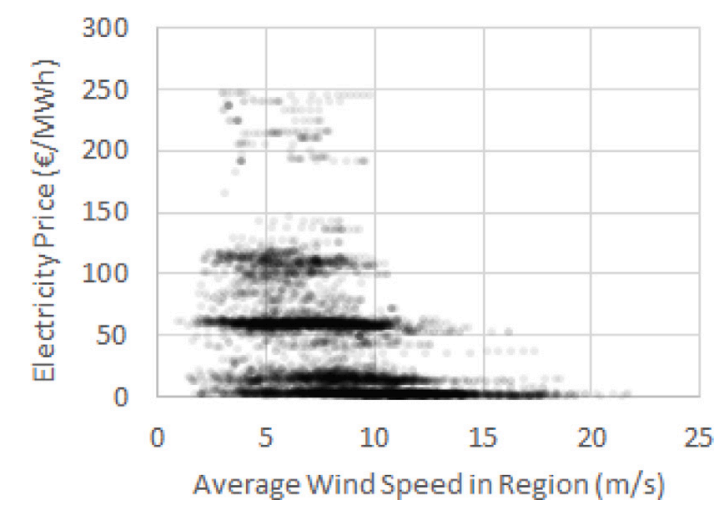

Fig. 15. Wind speed vs. electricity price in DK1, in 2045 , in the NoTrans $(+50 \%)$ scenario.

What Fig. 14 also shows is that when transmission is limited in the NoTrans scenarios, there is a large drop in hours with high electricity prices. While this may be counter intuitive, the energy system optimization invests in more dispatchable generation in the NoTrans scenario (to make up for the transmission constraints), which leads to less peaker plant usage. Furthermore, limiting transmission also leads to a reduction in the amount of near-zero electricity prices, once again due to more dispatchable generation being needed to meet demand. This also explains why mean electricity price is higher in the BASE scenarios than the NoTrans scenarios, as the large decrease in peaker usage leads to the mean dropping. However, during most of the year, electricity prices are higher in the NoTrans scenarios. Lastly, in the NoTrans scenario, the impact from LW technology can also be seen, as there is a clear decrease in the number of hours of near-zero electricity prices when comparing NoTrans $(+39 \%)$ and NoTrans (50\%).

Another interesting finding is how correlated electricity price and WS can become, especially in windier areas. In Figs. 15 and 16, the correlation between WS and electricity price in DK1 (Western Denmark) and DE4-S (Southern Germany) in 2045 can be seen visually. What this shows is that in DE4-S, there is no significant correlation between WS and electricity price (having only a correlation of .04), however in Western Denmark, there is a correlation of -.47, which is larger than most regions in the model. This finding is important because it will help in analysing potential wind farm revenues, which is discussed later in this subsection. At the same time, Fig. 15 and Fig. 16 also show that extending the cut-out speed to $25 \mathrm{~m} / \mathrm{s}$ may not be worth the extra capital cost, at least in DK1, since it appears that electricity

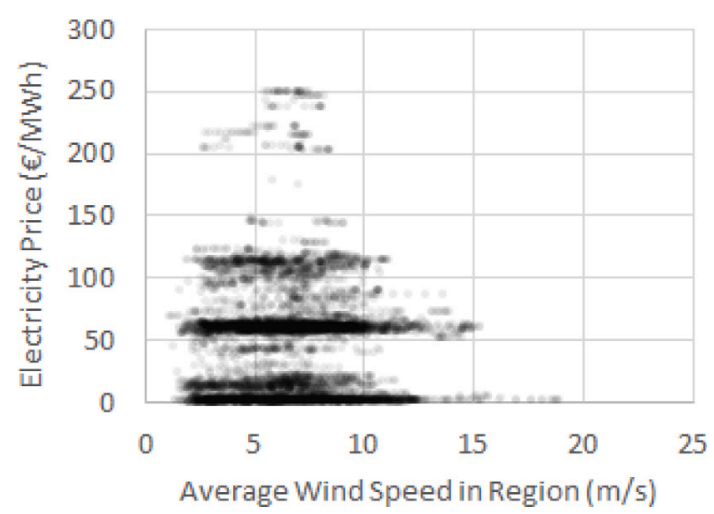

Fig. 16. Wind speed vs. electricity price in DE4-S in 2045 , in the NoTrans $(+50 \%)$ Scenario.

Table 7

Correlation between electricity price and wind speed in DK1 and DE4-S in 2045.

\begin{tabular}{llllll}
\hline Resource grade & \multicolumn{2}{l}{ NoTrans $(+50 \%)$} & & \multicolumn{2}{l}{ BASE $(+50 \%)$} \\
\cline { 2 - 3 } \cline { 6 - 6 } & DK1 & DE4-S & & DK1 & DE4-S \\
\hline RG A & -0.470 & -0.005 & & -0.352 & -0.048 \\
RG B & -0.466 & 0.004 & & -0.352 & -0.038 \\
RG C & -0.459 & 0.011 & & -0.345 & -0.026 \\
\hline
\end{tabular}

price is often near-zero when WS is above $13 \mathrm{~m} / \mathrm{s}$. A full table of WS vs electricity price correlations can be seen in Table B.1 in Appendix A.

Table 7 shows the correlation between electricity price and WS numerically. The takeaway here is that in areas with high wind penetration (e.g. Denmark), electricity prices could become correlated with WS. As further results will show, even a seemingly small correlation of -.47 would heavily impact wind farm revenue, specifically revenue/MWh. Should this occur, it will become a large problem for wind farms as they will struggle to generate revenue during windy periods. On the other hand, in areas with lower wind penetration, the correlation between electricity price and WS is not correlated. In the NoTrans $(+50 \%)$ scenario for example, even though DE4-S has more onshore wind capacity than DK1 and DK2's combined onshore and offshore wind capacity ( $29 \mathrm{GW}$ vs $16 \mathrm{GW}$ ), DE4-S has 40 times as much solar PV capacity (119 GW vs 3). The energy mix of these two regions can be found in Appendix A. In fact, in Southern Germany, electricity prices could become correlated with solar PV production, however this is outside the scope of this paper.

Table 8 shows the revenue/MW, and revenue/MWh that a marginal addition of each onshore turbine would have in the NoTrans $(+50 \%)$ scenario. There are a number of interesting findings that can be drawn from this table, starting with a look at DK1. What is shown is that in DK1 in 2045, the LW-13 has a revenue/MWh of $30.5 €$, while the SP335-HH100's revenue/MWh is only $21 €$. Since the SP335-HH100 is similar to turbines installed in Denmark today [35], it is clear that the LW-13 could provide danish wind farms a large boost in revenue that would not be captured in a simple LCOE calculation. Another interesting finding is that when comparing the SP198-HH150 the LW13 , again in DK1, we can see that the CF between the two is very close ( $59 \%$ vs $60 \%$ ), the revenue/MW is quite different (129k€vs 160 $\mathrm{k} €$ ). This is due to the difference in revenue/MWh, which is caused by the LW-13 producing much more electricity during periods of higher electricity prices than the SP198-HH150.

A comparison between the LW-13 and LW- 25 can also be made from observing Table 8. What we can see is that both in Denmark (DK1) and Southern Germany (DE4-S), the additional energy production the LW-25 generates due to having a much higher cut-out wind speed ( $25 \mathrm{~m} / \mathrm{s}$ vs $13 \mathrm{~m} / \mathrm{s}$ ) only leads to an increase of revenue/MW of $2.96 \%$ in Denmark and $2.25 \%$ in Southern Germany. In Denmark, this small 
Table 8

Potential onshore turbine revenue and CF in the NoTrans (+50\%) scenario in 2045.

\begin{tabular}{llll}
\hline & & DK1 | RG A & DE4-S | RG C \\
\hline \multirow{3}{*}{ SP335-HH100 } & CF & $43 \%$ & $20 \%$ \\
& Revenue/MW [€] & 79,365 & 54,347 \\
& Revenue/MWh [€] & 21.0 & 30.7 \\
\hline \multirow{3}{*}{ SP335-HH150 } & CF & $49 \%$ & $27 \%$ \\
& Revenue/MW [€] & 96,764 & 74,115 \\
& Revenue/MWh [€] & 22.5 & 31.6 \\
\hline \multirow{3}{*}{ SP277-HH100 } & CF & $47 \%$ & $23 \%$ \\
& Revenue/MW [€] & 90,164 & 62,236 \\
& Revenue/MWh [€] & 21.8 & 30.9 \\
\hline \multirow{3}{*}{ SP277-HH150 } & CF & $53 \%$ & $30 \%$ \\
& Revenue/MW [€] & 108,043 & 83,016 \\
& Revenue/MWh [€] & 23.4 & 31.8 \\
\hline \multirow{3}{*}{ SP198-HH100 } & CF & $54 \%$ & $29 \%$ \\
& Revenue/MW [€] & 111,763 & 78,546 \\
& Revenue/MWh [€] & 23.7 & 31.3 \\
\hline \multirow{3}{*}{ LW-25 } & CF & $59 \%$ & $35 \%$ \\
& Revenue/MW [€] & 129,025 & 99,626 \\
& Revenue/MWh [€] & 25.1 & 32.1 \\
\hline & CF & $60 \%$ & $43 \%$ \\
& Revenue/MW [€] & 159,867 & 122,523 \\
& Revenue/MWh [€] & 30.5 & 32.5 \\
\hline & RF & $68 \%$ & $44 \%$ \\
& Revenue/MW [€] & 164,608 & 125,274 \\
& & 27.7 & 32.2 \\
\hline
\end{tabular}

increase in revenue is due to electricity prices being near zero during hours of high winds, whereas in Southern Germany, the small increase is due to the fact that there are not many hours where wind speeds exceed $13 \mathrm{~m} / \mathrm{s}$.

The main finding here is that the LW-13 technology can outperform its LCOE compared to other wind technologies, particularly in regions with high wind penetration. This is because LCOE is based off of lifetime cost and lifetime electricity generation, and it does not take into account the price of electricity during the hours of generation. In other words, due to electricity price becoming correlated with wind speed (in DK1 in this example), the marginal addition of LW-13 earns higher revenue/MWh than a marginal addition of a conventional turbine, since it produces electricity during low wind hours when other turbines are not generating electricity and electricity prices are therefore higher on average. Furthermore, LW technology increases average electricity price by reducing the amount of near-zero electricity price hours, which alleviates the "self-cannibalization" effect and could allow all wind farms to earn more revenue. At the bottom of Table 8, a comparison is made between the LW-13 and the LW-25, which shows that although the LW-13 has a lower CF than the LW-25, being 4\% lower in DE4-S, $8 \%$ lower in DK1, it only generates $2 \%$ lower revenues in each location. This is an indication that extending the cut-out WS from $13 \mathrm{~m} / \mathrm{s}$ to $25 \mathrm{~m} / \mathrm{s}$ may be worth less than the additional 5\% CapEx that price point analysis pointed to earlier in this section, at least from the perspective of a wind farm owner.

\section{Discussion}

There are a number of key findings in this paper. The price points at which the LW-13 and LW-25 become competitive have been identified, as well as the possible impact that disallowing future transmission expansion has on LW investment. Furthermore, the impacts that the introduction of the LW technology could have on the system have been shown. Lastly, the impact LW technology has on electricity price has been investigated, and the potential wind farm revenue from each turbine technology has been calculated and analysed. To investigate the competitiveness of the LW-13 turbine, the discussion has been broken down into three different analyses: a technical analysis, an economic analysis, and a power system analysis.

\subsection{Technical analysis}

Two LW turbines were compared in this paper, one with a cut-off speed of $13 \mathrm{~m} / \mathrm{s}$ (LW-13), and one where the cut-off speed of the turbine was expanded to $25 \mathrm{~m} / \mathrm{s}$ (LW-25). While this paper finds that extending the cut-off WS leads to more investment in the LW turbine, particularly in RG A areas (the windiest areas of each region), the clear conclusion here is that low cut-out WS is ideal, particularly in energy systems with high wind penetration or low wind speeds.

The reason for this conclusion is that electricity price becomes negatively correlated with WS in energy systems with high wind penetration, which can be seen both in the energy model results and in the literature $[4,13,15]$. This correlation can also be seen in Denmark today, which can be seen in the next section in Fig. 17. This means during hours of high winds, electricity prices are usually low, and thus the revenue earned by wind farms during these hours are low. This finding can best be seen in at the bottom of Table 8, where the LW13 can be compared to the LW-25 in the year 2045. In DK1 (Western Denmark), even though the LW-13 has lower CF than the LW-25 $(60 \%$ vs $68 \%$ ), it would only earn $2.96 \%$ less revenue/MW due to the very low electricity prices when wind speeds are higher than $13 \mathrm{~m} / \mathrm{s}$ and higher electricity prices during low wind speeds. The upshot here is extending the cut-off WS from $13 \mathrm{~m} / \mathrm{s}$ to $25 \mathrm{~m} / \mathrm{s}$ only leads to a $\sim 3 \%$ increase in annual revenue/MW in Denmark, where by 2045 wind accounts for $80 \%$ of electricity generation. Meanwhile, extending the cut-out WS to $25 \mathrm{~m} / \mathrm{s}$ would likely increase blade mass by up to $33 \%$ based on the analysis in Section 2.1. Moreover the LW-25 would also contribute to overgeneration during high wind hours, which could lead to additional transmission constraints.

The same conclusion can be made for low WS areas, where extending the cut-out WS from $13 \mathrm{~m} / \mathrm{s}$ to $25 \mathrm{~m} / \mathrm{s}$ only lead to an increase in revenue/MW of $2.25 \%$ in Southern Germany, because there are simply very few hours of wind speeds above $13 \mathrm{~m} / \mathrm{s}$. In other words, extending the cut-out WS lead to a marginal increase in CF (44\% vs $43 \%$ ), which lead to a marginal increase in revenue/MW. The only regions where the LW-25 would likely outperform the LW-13 (in revenue terms) enough to justify an increase in cut-out WS would be in medium and high wind locations that have low wind penetration; however one also has to consider that in these regions, the LCOE of more convectional onshore turbines is much lower than LW-13/LW-25 LCOE as there are more high wind hours and less low wind hours. An LCOE comparison can be found in Appendix A, Figure A.5.

\subsection{Economic analysis}

The main finding here is that this LW technology could be competitive with conventional turbines in low wind areas. Even in the scenarios where the LW-13 investment cost was $2.48 \mathrm{M} € / \mathrm{MW}$ in 2025 ( $+45 \%$ scenarios), the energy system model invests heavily in LW-13. Starting at this price point, by 2045 the LW-13 sees 33 GW of investment in the BASE scenario and $105 \mathrm{GW}$ of investment in the NoTrans scenario (where endogenous transmission investment is disallowed). This increase in investment in the NoTrans scenario shows that LW technology has a much higher value in less flexible energy systems. Furthermore, there was earlier investment in LW technology in the NoTrans scenarios, already seeing $15 \mathrm{GW}$ of investment in 2025 compared to $4 \mathrm{GW}$ in the BASE scenario (at the $+39 \%$ price point), which can be seen in Fig. 12.

These findings also show that LW technology has value beyond its LCOE, as in the $+45 \%$ price scenarios, there is not one region in the model where the LW-13 has the lowest onshore wind LCOE, yet it sees significant investment in lower wind regions (LCOE for each turbine in each region can be seen in Figure A.5 in Appendix A).

While the energy model invests in LW technology in lower wind areas, an analysis on potential revenue has also been conducted that indicates that areas with high wind penetration (such as Denmark) 
could also benefit from LW technology. When observing the results in 2045 , one finding is that electricity price becomes negatively correlated with WS in areas with high wind penetration (e.g. Western Denmark), meaning that as WS increases, electricity price generally decreases. This finding can be seen in Table 7, where in 2045 the correlation between WS and electricity price in DK1 is found to be -0.35 in the BASE scenario and -0.47 in the NoTrans scenario. Using the hourly electricity prices for 2045, the revenue for each turbine was also calculated, shown in Table 8. The main finding here is that the LW-13 generates more revenue/MWh than conventional turbines, especially in areas with high wind penetration. This is due to there being higher electricity prices during lower wind hours and lower electricity prices during high wind hours, which can be seen in Fig. 15.

Since simple LCOE calculations are based off of CapEx, OpEx, and CF (and ignore the price at which electricity is sold at), this analysis indicates that using LCOE to gauge whether this LW-13 makes financial sense is a mistake. For example, in DK1, when comparing the LW-13 to the SP335-HH100 (a typical turbine installed Denmark today [35]), the LW-13 has a CF that is $40 \%$ higher than the SP335-HH100, which would indicate that it should generate $40 \%$ more revenue. This is not the case however, at least not in 2045 , as a marginal addition of the LW-13 would instead generate $101 \%$ more revenue than the SP335HH100 (based on Table 8). This clearly shows that we need to find a new way to compare non-dispatchable generation to take into not only lifetime cost and generation, but also value to the system and price at which electricity is sold at.

Research from Mills et al. has also found that low specific power, higher hub height turbines could have around a 0.7 \$/MWh savings to wind farm owners though lower spur line and interconnections costs/MWh (due to higher capacity factor) and better financing terms (due to lower variable AEP) [14]. This finding, combined with the potentially higher revenues found in this paper, makes a compelling case for the LW technology described in this paper.

\subsection{Power system analysis}

Another finding in this paper is that the introduction of LW technology into the Northern European energy system leads to decreases in transmission investment, solar PV investment, and offshore wind investment (shown in Figs. 9 and 10). This occurs due to the LW13 having higher capacity factor than other onshore turbines, thereby producing more electricity from the limited onshore wind capacity potential in the model. The more electricity generated from onshore turbines, the less electricity is needed from offshore turbines and PV generation. The higher capacity factor also leads to more consistent electricity production during hours of low and medium wind speeds and less overproduction during hours of high wind speeds, which leads to a reduction in transmission investment.

This LW technology is also found to impact electricity prices, causing fewer hours of near-zero prices. This occurs due to the LW-13 shutting off when wind speeds are high, causing less overproduction during times of higher wind speeds and leading to less hours of overproduction and therefore less hours of near-zero electricity prices.

Investment in LW technology can be seen the most in regions with the lowest wind speeds and/or the most transmission constraints, namely Germany, Poland, and Lithuania. This is because in low wind areas, the LCOE of the LW-13 is only slightly higher than conventional turbines, but generates significantly higher $\mathrm{CF}$, which adds value to the system as it reduces the need for flexibility during lower wind hours, leading to significant investment in these areas. Thus, based on the energy model results, there is a argument to be made for installing LW technology in low-wind areas, as it reduced the overall cost of the system even though in LCOE terms it was a more expensive option than the most competitive conventional turbine.
Table 9

Cumulative LW-13 investment in each scenario, by 2045

\begin{tabular}{llll}
\hline $\begin{array}{l}\text { Price point } \\
(-)\end{array}$ & $\begin{array}{l}2025 \mathrm{CapEx} \\
(\mathrm{M} € / \mathrm{MW})\end{array}$ & $\begin{array}{l}\text { BASE } \\
(\mathrm{GW})\end{array}$ & $\begin{array}{l}\text { NoTrans } \\
(\mathrm{GW})\end{array}$ \\
\hline$+28 \%$ & 2.19 & 286 & 288 \\
$+34 \%$ & 2.29 & 220 & 219 \\
$+39 \%$ & 2.38 & 134 & 176 \\
$+45 \%$ & 2.48 & 33 & 105 \\
$+50 \%$ & 2.57 & 0 & 30 \\
\hline
\end{tabular}

\subsection{Areas for improvement}

There are of course many aspects that could be improved in this study. For instance, only two LW turbines were analysed, the LW-13 and LW-25. What could improve the analysis is to include more LW turbines with various cut-out WS to see which cut-out WS is the most optimal. Along the same lines, more grid scenarios could be added to further analyse how different aspects of the energy system impact LW investment, such as energy storage, district heating investment, and the removal of sector coupling. Similarly, analysing more LW CapEx prices could be added to the analysis, especially in combination with more grid scenarios as it could be that there could be investment at costs that are higher than the $+50 \%$ scenarios analysed in this paper (since there was investment at the $+50 \%$ price point in the NoTrans scenario).

One aspect that was neglected was looking into wind farm topology. In this paper, each wind technology is built such that each wind technology had a topology that led to having $51 \mathrm{MW} / \mathrm{km}^{2}$. This meant that the larger rotor turbines, namely the LW turbines, were spaced closer together than they would be normally. Thus, one area to look into in the future would be how the results would change if turbines were placed further apart or even closer together (i.e. run the same model with MW $/ \mathrm{km}^{2}$ varying from 40 to 60 ). The trade-off between increasing MW or CF would an interesting and novel analysis.

Lastly, a deep dive into how much the LW-13 turbine would actually cost could add value to this research, as the price sensitivity could be done at higher resolutions around the calculated CapEx. Using WISDEM and the DEA technology catalogue, the LW-13 is found to have a CapEx of $2.48 \mathrm{M} € / \mathrm{MW}$ in 2025 (resulting is the CapEx used in the $+45 \%$ scenario), using the same scaling factor used for the other turbines (1.296). However, a more detailed study would need to be conducted, as the WISDEM result is likely too high since it was made to calculate the CapEx of conventional turbines, assuming conventional loads which are much higher than the LW-13 is calculated to have in [6].

\section{Conclusions}

This paper has investigated the competitiveness of the LW-13 onshore wind turbine (described in [6]), which has a specific power of $100 \mathrm{~W} / \mathrm{m}^{2}$ and a cut-out WS of $13 \mathrm{~m} / \mathrm{s}$. The purpose of this turbine is twofold, to generate high FLH in low wind regions (which is achieved by having a specific power of $100 \mathrm{~W} / \mathrm{m}^{2}$ ) and to not contribute to overgeneration during high wind hours in regions with high wind penetration (which is achieved through the $13 \mathrm{~m} / \mathrm{s}$ cut-out WS). Furthermore, this low cut-out wind speed could allow turbine manufactures to build thinner, lighter blades, which would reduce the CapEx of the turbine. The main takeaway from this work is that the LW13 turbine has the potential to be competitive in both low wind areas (based on the energy system optimization results) and areas with high wind penetration (based on the hourly revenue analysis). Regions with medium to high wind speeds and low wind penetration are suboptimal for LW-13 investment as there is a higher likelihood of wind speeds above $13 \mathrm{~m} / \mathrm{s}$ and no improvement in revenue/MWh to be had. 


\subsection{Key findings}

From a system optimization standpoint, when modelled in direct competition with six conventional turbines, the LW turbine sees $33 \mathrm{GW}$ of investment at a $+45 \%$ price point by 2045 , primarily in low wind regions of the model. The results at each price point are summarized in Table 9. Furthermore, when endogenous transmission investment is disallowed (where the transmission system remains unchanged from today), the LW-13 sees $30 \mathrm{GW}$ of investment at a $+50 \%$ price point by 2045 , once again in low wind regions of the model.

However, there is also an argument to be made for LW-13 investment from the standpoint of wind farm owners, at least in regions with high wind penetration (such as Denmark), as the LW-13 could receive more revenue/MWh than conventional turbines since it generates electricity during times that conventional turbines do not. Compared to turbines that were installed in Denmark in 2018, with a mean specific power of $330 \mathrm{~W} / \mathrm{m}^{2}$ [35] (similar to the SP335-HH100 turbine in this paper), the LW-13 has the potential to receive double the revenue/MW in 2045 in Denmark. This example is relevant because wind penetration levels in Denmark exceeded $80 \%$ by 2045 in this study, where electricity price was negatively correlated with WS.

The energy system optimization results also showed that large amounts of LW-13 investment led to decreases in interregional transmission, since it both generates more electricity during periods of low wind (reducing the number of hours of high net load) and cutting production during periods of high wind speeds (leading to less overproduction). Combined, these factors lead to a reduction of endogenous transmission investment by up to $15 \%$ (measured in TWkm). The introduction of the LW-13 also decreased the number of hours with near-zero electricity price, as it led to less hours of overgeneration.

Lastly, the reduction in cut-out WS from a more traditional $25 \mathrm{~m} / \mathrm{s}$ to $13 \mathrm{~m} / \mathrm{s}$ appears to reduce revenue/MW in 2045 by $2.2 \%$ in low wind regions (due to having few hours of high wind speeds) and $3 \%$ in regions with high wind penetration (as electricity prices fall to nearzero during high wind hours). This reduction in cut-out WS could also reduce the cost of the turbine significantly since it could reduce blade mass by up to $33 \%$. If this is indeed the case, there is a case to be made that reducing the cut-out WS of turbines being installed in regions with high wind penetration is optimal from both a grid balancing perspective and a wind farm owner's perspective (assuming lighter blades lead to cheaper turbines).

\subsection{Current \& future trends}

While much of this paper analysed Northern and Central Europe's energy system in 2045, the problems that the LW-13 addresses (namely reducing the self-cannibalization effect and overgeneration during high wind hours) already exist today. By looking at historical data from Nordpool it can be shown that in 2019, electricity price in DK1 has a negative correlation with wind farm capacity factor of -.398 [38], which can be seen visually in Fig. 17. While Denmark is a unique case today, as it currently has nearly 50\% wind penetration [39], other Northern European countries will likely reach this point in the future as well if they are to transition to a carbon neutral energy system by 2050.

Likewise, major transmission congestion is occurring today between Denmark and Germany, where in 2020 Germany's TSO Tennet paid danish wind farms to curtail 1.46 TWh of electricity production, which is $4.3 \%$ of Denmark's annual electricity consumption [39].

Both wind penetration and transmission congestion are likely to increase in the future as the Northern and Central European energy system continues to decarbonize. This means the need for technologies like the LW-13 are likely to increase as time goes on, especially in areas with high wind penetration.

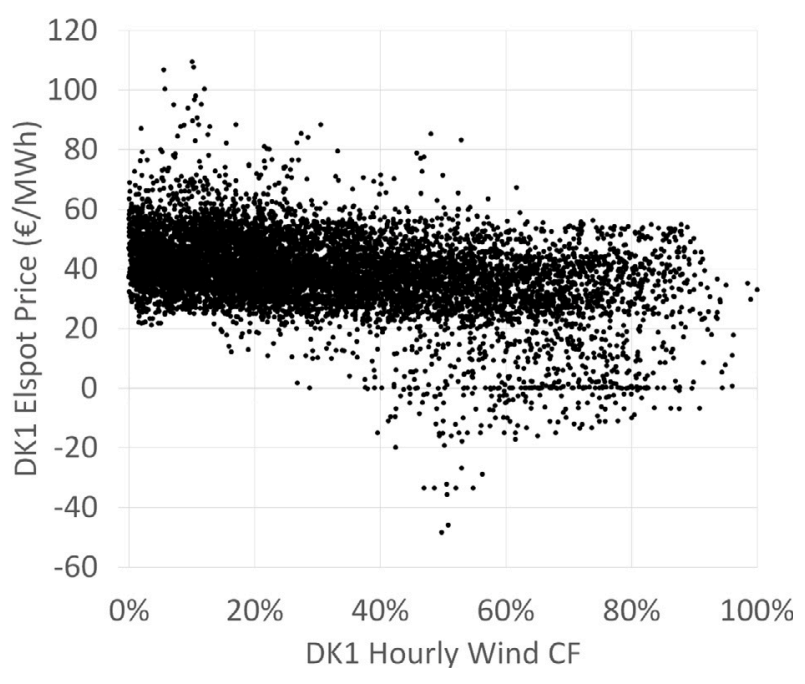

Fig. 17. Electricity price vs wind farm CF in DK1 in 2019 [38].

\section{CRediT authorship contribution statement}

Philip Swisher: Conceptualization, Methodology, Software, Validation, Formal analysis, Investigation, Data curation, Writing - original draft, Writing - review \& editing, Visualization. Juan Pablo Murcia Leon: Methodology, Software, Resources, Writing - original draft, Visualization. Juan Gea-Bermúdez: Conceptualization, Methodology, Software, Resources, Writing - review \& editing. Matti Koivisto: Conceptualization, Methodology, Writing - original draft, Writing - review \& editing, Visualization, Supervision, Project administration. Helge Aagaard Madsen: Conceptualization, Methodology, Writing - review \& editing, Funding acquisition. Marie Münster: Writing - review \& editing, Supervision, Project administration.

\section{Declaration of competing interest}

The authors declare that they have no known competing financial interests or personal relationships that could have appeared to influence the work reported in this paper.

\section{Acknowledgements}

The funding from the Danish Energy Agency EUDP2019-I: Project number. 64019-0074, "The Low-Wind turbine concept for optimal system integration" is acknowledged. Matti Koivisto acknowledges support from the PSfuture project, Denmark (La Cour Fellowship, DTU Wind Energy). Juan Gea-Bermúdez acknowledges the NSON-DK and Flex4RES projects funded by the Danish Energy Agency, EUDP (grant 64018-0032; previously ForskEL) and Nordic Energy Research, Norway (grant 76084), respectively.

\section{Appendix A. Supplementary data}

Supplementary material related to this article can be found online at https://doi.org/10.1016/j.apenergy.2021.118043.

\section{References}

[1] European Commission. European Green Deal https://ec.europa.eu/info/strategy/ priorities-2019-2024/european-green-deal_en (Accessed: April 2020).

[2] European Commission. Establishing the Framework for Achieving Climate Neutrality and Amending Regulation (EU) 2018/1999 (European Climate Law), https://eur-lex.europa.eu/legal-content/EN/TXT/?qid=1588581905912\& uri=CELEX:52020PC0080 (Accessed: April 2020). 
[3] Winter, Wilhelm, European Wind Integration Study, ENTSO-E (March 2010) URL http://www.wind-integration.eu/downloads/library/EWIS_Final_Report.pdf.

[4] López Prol J, Steininger KW, Zilberman D. The cannibalization effect of wind and solar in the california wholesale electricity market. Energy Econ 2020;85:104552. http://dx.doi.org/10.1016/j.eneco.2019.104552, URL https:// linkinghub.elsevier.com/retrieve/pii/S0140988319303470.

[5] Riva AD, Hethey J, Vitina A, Lantz EJ. IEA Wind TCP Task 26: Impacts of Wind Turbine Technology on the System Value of Wind in Europe. NREL/TP-6A2070337, 1437346, 2017, http://dx.doi.org/10.2172/1437346, URL http://www. osti.gov/servlets/purl/1437346/.

[6] Madsen HA, Zahle F, Meng F, Barlas T, Rasmussen F, Rudolf RT. Initial performance and load analysis of the LowWind turbine in comparison with a conventional turbine. J Phys Conf Ser 2020;1618(3):032011. http://dx.doi.org/ 10.1088/1742-6596/1618/3/032011.

[7] Wiser R, Bolinger M, Barbose G, Darghouth N, Hoen B, Mills A, Rand J, Millstein D, Jeong S, Porter K, Disanti N, Oteri F. 2018 wind technologies market report. 2018, p. 103.

[8] Gil Masters. Renewable and Efficient Electric Power Systems. 2004.

[9] Riva AD, Hethey J, Luers S, Wallasch A-K, Rehfeldt K, Duffy A, Weir DE, Stenkvist M, Uihlein A, Stehly T, Lantz E. IEA Wind TCP Task 26: Wind Technology, Cost, and Performance Trends in Denmark, Germany, Ireland, Norway, Sweden, the European Union, and the United States: 2008-2016. 2018.

[10] Riva AD, Hethey J, Lüers S, Wallasch A-K, Rehfeldt K, Duffy A, Weir DE, Stenkvist M, Uihlein A, Stehly T, Lantz E, Wiser R. IEA Wind TCP Task 26: Cost of Wind Energy Phase 3 Final Technical Report.

[11] Mills A. Implications of wide-area geographic diversity for short- term variability of solar power. 2010, URL https://escholarship.org/uc/item/9mz3w055.

[12] Mills A. Changes in the economic value of variable generation at high penetration levels: A pilot case study of California. 2012, URL https://escholarship.org/uc/ item/2g7677hn.

[13] Mills A, Wiser R. Strategies for Mitigating the Reduction in Economic Value of Variable Generation with Increasing Penetration Levels. LBNL-6590E, 1129522, 2014, http://dx.doi.org/10.2172/1129522, URL http://www.osti.gov/servlets/ purl/1129522/.

[14] Wiser R, Millstein D, Bolinger M, Jeong S, Mills A. Wind power marketvalue enhancements through larger rotors and taller towers. 2020, https://www.esig.energy/download/wind-power-market-value-enhancementsthrough-larger-rotors-and-taller-towers-lbnl-july-2020/.

[15] Hirth L, Müller S. System-friendly wind power. Energy Econ 2016;56:51-63. http://dx.doi.org/10.1016/j.eneco.2016.02.016, URL https://linkinghub.elsevier. com/retrieve/pii/S0140988316300317.

[16] May N, Neuhoff K, Borggrefe F. Market incentives for system-friendly designs of wind turbines. DIW Economic Bulletin 2015;5(24):313-21, https://ideas.repec. org/a/diw/diwdeb/2015-24-1.html.

[17] May N. The impact of wind power support schemes on technology choices. Energy Econ 2017;65:343-54. http://dx.doi.org/10.1016/j.eneco.2017.05.017, URL http://www.sciencedirect.com/science/article/pii/S0140988317301810.

[18] Riva AD. System value of wind power - an analysis of the effects of wind turbine design. (Master's thesis, Technical University of Denmark), 2016, Semantic Scholar. https://www.semanticscholar.org/ paper/System-Value-of-Wind-Power-\%3A-An-analysis-of-the-of-Riva/ 7e184e749a481dc198c622987f1d2fe3d18ed18e.

[19] Bortolotti P, Berry DS, Murray R, Gaertner E, Jenne DS, Damiani RR, Barter GE, Dykes KL. A detailed wind turbine blade cost model. NREL/TP-5000-73585, 1529217, 2019, http://dx.doi.org/10.2172/1529217, URL http://www.osti.gov/ servlets/purl/1529217/.

[20] Stehly T, Beiter P. 2018 cost of wind energy review. 2019, p. 71

[21] Bortolotti P, Tarres HC, Dykes K, Merz K, Sethuraman L, Verelst D, Zahle F. IEA Wind TCP Task 37: Systems Engineering in Wind Energy - WP2.1 Reference Wind Turbines, https://www.nrel.gov/docs/fy19osti/73492.pdf.
[22] van der Laan MP, Sø rensen NN, Réthoré P-E, Mann J, Kelly MC, Troldborg N, Hansen KS, Murcia JP. The $\kappa-\epsilon-f_{P}$ model applied to wind farms. Wind Energy 2015;18(12):2065-84.

[23] Koivisto M, Das K, Guo F, Sørensen P, Nuño E, Cutululis N, Maule P. Using time series simulation tools for assessing the effects of variable renewable energy generation on power and energy systems. Wiley Interdiscip. Rev.: Energy Environ. 2019;8(3):e329. http://dx.doi.org/10.1002/wene.329.

[24] Nuño E, Maule P, Hahmann A, Cutululis N, Sørensen P, Karagali I. Simulation of transcontinental wind and solar PV generation time series. 2018;118:425-36. http://dx.doi.org/10.1016/j.renene.2017.11.039.

[25] Koivisto M, Plakas K, Ellmann EH, Davis N, Sørensen P. Application of microscale wind and detailed wind power plant data in large-scale wind generation simulations. 2021;190:106638. http://dx.doi.org/10.1016/j.epsr.2020.106638.

[26] Wiese F, Bramstoft R, Koduvere H, Pizarro Alonso A, Balyk O, Kirkerud JG, Tveten ÅG, Bolkesjø TF, Münster M, Ravn H. Balmorel open source energy system model. Energy Strategy Rev. 2018;20:26-34. http://dx.doi. org/10.1016/j.esr.2018.01.003, URL https://linkinghub.elsevier.com/retrieve/ pii/S2211467X18300038.

[27] Github. Balmorel Model. https://github.com/balmorelcommunity/Balmorel.

[28] Gea-Bermúdez J, Pade L-L, Koivisto MJ, Ravn H. Optimal generation and transmission development of the north sea region: Impact of grid architecture and planning horizon. Energy 2020;191:116512. http://dx.doi.org/10. 1016/j.energy.2019.116512, URL http://www.sciencedirect.com/science/article/ pii/S0360544219322078.

[29] Gea-Bermúdez J, Das K, Koduvere H, Koivisto M. Day-ahead market modelling of large-scale highly-renewable multi-energy systems: analysis of the North Sea region towards 2050. Energies 2021;14:88, https://doi.org/10.3390/ en14010088.

[30] Gea-Bermúdez J, Pade L-L, Koivisto MJ, Ravn H. Optimal generation and transmission development of the north sea region: Impact of grid architecture and planning horizon. Energy 2020;191:116512. http://dx.doi.org/10. 1016/j.energy.2019.116512, URL http://www.sciencedirect.com/science/article/ pii/S0360544219322078.

[31] Juan G-B, Münster M, Jensen IG, Koivisto MJ, Kirkerud J, kuang Chen Y. The role of sector coupling in the green transition: A least-cost energy system development in North Europe towards 2050. 2020, http://dx.doi.org/10.36227/ techrxiv.12933071.v1.

[32] Nordic Energy Research and International Energy Agency. Nordic energy technology perspectives 2016 report. 2016, URL http://www.nordicenergy.org/project/ nordic-energytechnology-perspectives/.

[33] https://www.nrel.gov/wind/systems-engineering-models-tools.html.

[34] https://wisdem.readthedocs.io/en/master/index.html.

[35] Danish Energy Agency. Technology catalogues. 2020, URL: https://ens.dk/en/ our-services/projections-and-models/technologydata.

[36] Zhou Y, Gu A. Learning curve analysis of wind power and photovoltaics technology in US: cost reduction and the importance of research, development and demonstration. Sustainability 2019;11:2310.

[37] Murcia Leon J, Koivisto M, Sørensen P, Magnant P. Power fluctuations in high installation density offshore wind fleets. Wind Energy Sci. Discuss. 2020;2020:123. http://dx.doi.org/10.5194/wes-2020-95, URL https://wes.copernicus.org/ preprints/wes-2020-95/.

[38] https://www.nordpoolgroup.com/historical-market-data/.

[39] Energinet. Brug for fintælling: 2020 i uhyre tæt opløb med 2019 om dansk vindrekord. 2021. 